\title{
A new conception and subsequent taxonomy of clinical psychological problems
}

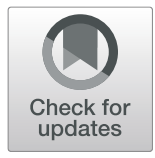

Gary M. Bakker®D

\begin{abstract}
Background: A taxonomy of the objects of study, theory, assessment, and intervention is critical to the development of all clinical sciences. Clinical psychology has been conceptually and administratively dominated by the taxonomy of an adjacent discipline - psychiatry's Diagnostic and statistical manual of mental disorders (DSM). Many have called for a 'paradigm shift' away from a medical nosology of diseases toward clinical psychology's own taxonomy of clinical psychological problems (CPPs), without being able to specify what is to be listed and classified.

Main text: An examination of DSM's problems for clinical psychology, especially its lack of clinical utility, and a search for the essence of CPPs in what clinical psychologists actually do, leads to the proposal that: The critical psychologicallevel phenomenon underlying CPPs is the occurrence of 'problem-maintaining circles' (PMCs) of causally related cognitions, emotions, behaviours, and/or stimuli. This concept provides an empirically-derived, theory-based, treatment-relevant, categorical, essentialist, parsimonious, and nonstigmatizing definition of CPPs. It distinguishes psychological problems in which PMCs have not (yet?) formed, and which may respond to 'counseling', clinical psychological problems in which active PMCs require clinical intervention, and psychopathological problems which are unlikely to be 'cured' by PMC-breaking alone.

Conclusion: A subsequent classification and coding system of PMCs is proposed, and expected benefits to research, communication, and the quality of case formulation in clinical psychology are described, reliant upon a development effort of some meaningful fraction of that which has been devoted to the DSM.
\end{abstract}

Keywords: Case formulation, Clinical psychological problems, Functional analysis, Mental disorders, Symptom networks, Problem-maintaining circles, Taxonomy, Transdiagnostic

\section{The need for a new conception of clinical psychological problems}

The focus, advancement, and direction of any scientific discipline is critically and essentially dependent upon the basic conceptualization that it holds of its subject matter [1-3], and upon the subsequent taxonomy or listing which it develops of that subject matter $[4,5]$. Chemistry has its periodic table. Zoology and botany list and categorize species. Astronomy has developed its star charts, galaxy taxonomy, and so forth.

In order to avoid unwarranted assumptions, the objects of systematic observation and experiment, theory development, assessment, and intervention within the science and practice of clinical psychology - it being

Correspondence: gary.bakker@bigpond.com

School of Medicine, University of Tasmania, Locked Bag 1377, Launceston,

Tasmania 7250, Australia a remedial discipline - may most simply be called clinical psychological problems (CPPs). CPPs have, over time, variously been conceived as instances of demonic possession [6], moral failings [7], deeplyrooted psychodynamic pathologies, observable patterns of maladaptive behaviour, or internal states fundamentally grounded in biology [8]. Each alternative conceptualisation has entailed its own ad hoc or systematised taxonomy of psychological-level problems.

Since the publication of the third edition of the American Psychiatric Association's Diagnostic and statistical manual of mental disorders (DSM) [9] the first edition to be based heavily on a medical model of 'mental disorders' (closely paralleled by the WHO's International Classification of Diseases) - the conception of CPPs as biologically-based internal states has come to dominate, and the DSM has become clinical psychology's de facto problem 
taxonomy. This has led to and cemented the assumption that CPPs are solely and entirely mental disorders. This assumption has resulted in many widely recognised and irreconcilable problems for the discipline and profession of clinical psychology.

(The soon to be implemented latest iteration of WHO's ICD classification - ICD-11 - acknowledges these problems more than DSM-5 does, and its response will be described shortly.)

The publication of the latest edition of this taxonomy, DSM-5 [10], has solved none of the problems alluded to [11-16], prompting the British Psychological Society's Division of Clinical Psychology to release a consensus statement on psychiatric diagnosis - Position Statement on the Classification of Behaviour and Experience in Relation to Functional Psychiatric Diagnoses: Time for a Paradigm Shift [17] - which summarized DSM's limitations and deficiencies for clinical psychology. It concluded that "the current classification system as outlined in DSM...has significant conceptual and empirical limitations, consequently there is a need for a paradigm shift in relation to the experiences that these diagnoses refer to, towards a conceptual system which is no longer based on a 'disease' model" (p.1).

However, beyond suggesting that "such an approach would need to be multifactorial, to contextualise distress and behaviour, and to acknowledge the complexity of the interactions involved" (p.3), and that it should be "in keeping with the core principles of formulation in clinical psychology" [17], the Division did not propose a precise focus or the content of such an alternative conceptual taxonomy that would satisfy this paradigm shift. It is insufficient to point up the limitations of a conceptual model of CPPs if a superior one cannot be proffered, and "at present there is no consensus on what an alternative, universal theory of what maintains and exacerbates psychological distress might look like" [44].

If we are to develop such a radical reconceptualization of CPPs, to foster "a true 'Kuhnian' revolution” ([18] p.1935) in clinical psychology, and to develop a subsequent taxonomy of such, then the nature and essence of these new CPPs may be discernible in two ways: (1) The precise nature of the recognised inadequacies and incompatibilities of the mental disorder model for clinical psychology can point us toward a more useful and relevant conceptualization of CPPs; And (2) what clinical psychologists actually address in their research and practice may be drawn and distilled to extract the true essence of CPPs.

So firstly, what can the problems and incompatibilities for clinical psychology of psychiatry's DSM and its 'mental disorders' model teach us about the essence of CPPs?
Psychiatry is more biological-level; clinical psychology is more psychological-level

Psychiatry, as a branch of medicine, has a much greater focus on biological-level assessment, explanation, and intervention than has clinical psychology. Hence, its DSM lists.

'mental disorders', 'diagnosed' by the identification of a 'syndrome' of 'symptoms', which are assumed to be manifestations of a 'pathological condition' [19, 20].

This 'nosology of diseases' [21] based not on empirical evidence, but on clinical authority and historical tradition [22], has been problematic for psychiatry itself [13, 23-26], let alone for clinical psychology. It has been plagued by such major problems as excessive rates of comorbidity $[27,28]$, which may be an indicator of arbitrary boundaries between its disorders $[29,30]$, by the broad heterogeneity within its diagnosed groups [21, $31-33]$, and by the fact that none of the putative underlying disease processes have been uncovered in the 35 years of research since DSM-III was published [25, 3437]. The search for biological etiology has greatly disappointed [38, 39], suggesting that psychiatric diagnosis has oversimplified psychopathology [40].

DSM and the ICD, meantime, have been poor guides to even psychopharmacological treatment selection [41, 42], let alone to psychological therapy selection. Psychiatric drugs are frequently prescribed "outside their license", as when chlorpromazine is administered for anxiety or insomnia, thioridazine (another antipsychotic) for alcohol withdrawal, and benzodiazepines for "pretty much everything... The classification of mental health conditions gives us a false sense of order...It has little or no relevance to psychotropic drug action" ([43] p.225).

As part of the development of ICD-11, First et al. [44] surveyed 1764 mental health professionals, mainly psychiatrists, and found that the majority used ICD-10 or DSM-5 for administrative or billing purposes only. They rated such taxonomies as least useful for treatment selection and determining prognosis.

Psychiatry's own response to these acknowledged problems has been to redouble its conceptual biological insistence. For example, the National Institutes of Mental Health are developing a Research Domain Criteria (RDoC) framework [45] which, even more than DSM, conceptualises mental illnesses as brain disorders (latent disease constructs), but which seeks to identify them through objective behavioural tests and neurobiological measures such as genetic tests and neuroimaging, rather than through topographical symptom checklists. This response to DSM's failures has been described as a shift from the biopsychosocial model of mental disorders to a "bio-bio-bio model" [46]. It is much more a framework for biologically-oriented research [47] than a clinical replacement for the ICD or DSM [48]. While it tries to be 
more etiological and dimensional than those systems, its clinical usefulness lies well into the future [49].

The RDoC approach is therefore not at all a solution to clinical psychology's problems with the conception of CPPs as diagnosable mental disorders, which are less to do with the technical limitations of diagnosis and more to do with a conceptual mismatch. The proposers and developers of the $\mathrm{RDoC}$ project have attempted to circumvent the problem that heterogeneous symptom profiles among diagnosed groups are likely to encompass a large number of biologically distinct entities [50]. But clinical psychologists' concerns are that these groups are likely to encompass a large number of psychologically distinct entities.

So even were the $\mathrm{RDoC}$ project to improve diagnostic reliability, validity, and clinical utility for psychiatrists, it would still offer no greater attraction to clinical psychology. Clinical psychologists as a group are not as biologically focused or trained, do not prescribe medications or administer ECT, and in fact in practice rarely and reluctantly diagnose [51-53]. Instead, they construct case formulations at a psychological level [54].

The idea that CPPs can and should be reducible to presumed underlying neurobiological conditions which are somehow more basic, real, or 'scientific' than psychological-level formulations is not helpful [12], not logical [55], and, for almost all CPPs, is theoretically premature [56]. The psychological and the biological are different levels of analysis, assessment, and intervention [57], and any alignment of phenomena at these two levels is, by definition, correlational, not causal [55]. It is no more likely that all CPPs will be reduced in the future to neurobiological conditions than that the geological study of earthquakes will be reduced to molecular theory ([57] p. 508).

While it is possible and desirable to theoretically unify the social sciences and biology, the notion of abandoning the principles, theories, vocabulary, and laws of the social sciences in favour of lower-level terms is a "preposterous" proposition [58], which would result in such theses as "A Comparison of Keats and Shelley from the Molecular Point of View" or "The Role of Oxygen Atoms in Supply-Side Economics". Such "greedy reductionism" can arise when "in their zeal to explain too much too fast, scientists and philosophers often underestimate the complexities, trying to skip whole layers or levels of theory" ([58] p.82). "Mental disorders may be studied at different levels of analysis (e.g. molecular genetics, neurochemistry, cognitive neuroscience, personality, environment), and no level is inherently superior or fundamental to any other" ([12] p.856).

Clinical psychologists, when they operate within an adjacent level of analysis - in this case a psychiatric one will lose a large, perhaps critical, amount of psychologically-relevant information. "Psychiatrists using the DSM diagnosis 'major depression' tend to mingle bereaved patients with both those afflicted by classic melancholia and those demoralized by circumstances" ([59] p.1854). So when clinical psychologists allow themselves to be diverted from the study and psychological-level formulation of CPPs to research into the treatment of DSMdiagnosed mental disorders, this means that a 19 year old survivor of 14 years of sexual abuse within her dysfunctional family, who is now sad and amotivational every day, will be regarded as experiencing precisely the same CPP as a 73 year old recently bereaved widower who is also sad and amotivational every day, because these people share some 'symptoms' - some topographical similarities. They will also find themselves in the same experimental or control group in a clinical trial of a particular cognitive therapy or antidepressant medication, and conclusions about efficacy will then be extended to other people with even more diverse CPPs, because they allegedly have the same mental disorder.

It is highly likely that some CPPs currently regarded or labelled as mental disorders are most usefully assessed, diagnosed, and treated within a medical model, but that some do not conform well to this level of analysis, and will respond better when assessed and addressed at a psychological level [59-61]. "Psychiatric diagnoses differ in the sorts of categories that best capture them" ([60] p.204). Some may be more categorical than others [62]. There is some evidence, for example, that anorexia nervosa may be much less culture-bound and more heritable than bulimia nervosa [63], and so may be less socially constructed, more categorical, and a different 'kind' of thing. Schizophrenia and a simple reactive dog phobia are also likely to represent different classes of CPP in this light. The former more comfortably rests within a taxonomy of 'mental disorders' such as the DSM. A reactive dog phobia, on the other hand, may be more conceptually concordant with clinical psychology's own parallel purely psychologicallevel taxonomy of CPPs.

It will be a long time - if ever - before a complicated bereavement is fully explained by reference to a particular neural bundle, or treated solely with a localized electrical zap or a 'complicated bereavement pill'. Clinical psychology and biological psychiatry are different disciplines, operating at adjacent but different levels of analysis, and neither should subsume the other.

Our new conception of CPPs, and its subsequent taxonomy, will therefore centre on psychological-level states and processes - involving cognitions, emotions, behaviours, and situations or stimuli - and not on biological-level ones.

\section{Mental disorders are social constructions; they have no essence}

Another major problem with equating CPPs with mental disorders is that this subsumption represents relegation to a less developed, less theoretically robust, less 
therapeutically relevant level of analysis. This is an inevitable consequence of the fact that, whereas our theoretical knowledge of the processes, functions, and mechanisms underlying CPPs has grown greatly, DSM's listing of mental disorders began and has remained stolidly atheoretical $[8,32,64,65]$. DSM has made no claims about underlying mechanisms, functional processes, pathophysiology, etiology, and hence treatment implications of its mental disorders, and is therefore a "weak medical model" [66].

This deliberate policy was originally so as to accommodate a large number of theoretical orientations from a range of professions or disciplines [32, 35], but also more recently because, as previously described, the medical model has largely failed to further our understanding of the heterogeneous assortment of disorders the DSM lists [21]. The sluggish pace of discovery in psychiatry has been attributed, in part, to the limited validity and the arbitrariness of traditional diagnoses [67].

So, whereas a clinical psychologist will see a CPP involving problematic social anxiety, for example, as a psychological-level persisting negative process that requires case formulation and specific subsequent psychological-level intervention, according to DSM a Social Anxiety Disorder is a state or condition identified (but not explained) by its symptoms. How do we know that Bill has a Social Anxiety Disorder? He shows enough symptoms. What caused these symptoms? His Social Anxiety Disorder. There is no evidence that the mental disorder or mental illness called "Social Anxiety Disorder (Social Phobia)" (DSM300.23) actually exists. It has no 'essence'. There are no reliable or validated biological markers or measures outside clinical psychological judgement that can detect this illness. It is defined by its effects, which are attributed to its existence [52]. It is an assumption - a convention - constructed for sociological or political reasons, just as the disease model of alcohol problems and the chemical imbalance theory of depression were. They were developed in an attempt to reduce stigma or encourage people to take their antidepressants. But no evidence supportive of their veracity has emerged since.

So the concept of 'mental disorders' is inadequate to supplant that of CPPs because it is descriptive only not at all explanatory. But such disorders are therefore also inevitably vaguely and arbitrarily defined and demarcated. "Diagnostic criteria [in psychiatry] shift and sway like in no other area of medicine" [43]. The DSM meanders between at least seven different criteria in distinguishing non-problems from problems-deservingtherapy (mental disorders). At different times DSM specifies: (i) A certain symptom cluster. Three or more symptoms from a field of seven are required to diagnose an Antisocial Personality Disorder. (ii) A certain level of distress. In OCD "the obsessions or compulsions... cause clinically significant distress". (iii) A level of dysfunction. This is required for a diagnosis of Specific Phobia. (iv) A certain type of etiology. This marks a Posttraumatic Stress Disorder (PTSD) or a Substance-Induced Sexual Dysfunction. (v) A statistical deviation. To diagnose a Female Orgasmic Disorder requires a "marked infrequency" of orgasms. (vi) The chemistry involved. This determines an Alcohol-Related Disorder. And (vii) duration is a criterion determining the presence of an Acute Stress Disorder or Dysthymia [10]. One or two clear conceptual criteria to distinguish CPPs from 'normal problems in life' would be much preferred.

When arbitrary categories are forced onto dimensional phenomena like symptoms, then both reliability and validity have been shown to suffer [68-70]. Not only have no biological markers for the common mental disorders been uncovered, but this arbitrarily interchangeable collection of criteria for determining their presence means that not a single mental disorder has been established as a discrete categorical entity, as opposed to a dimensional outlier [71, 72].

This conceptual vacuum has left 'mental disorders' as merely social constructions [60], 'open concepts' [73], or 'practical kinds' $[15,40]$ without a true defining essence [27], and has resulted in intractable and interminable debates among psychologists and psychiatrists as to what ultimately defines a mental disorder [53]. Hence we have seen the inclusion and then exclusion in 1974 of homosexuality [74], and historical arguments over 'childhood masturbation disorder' and 'lack of vaginal orgasm' [75]. Right up to today, clinicians and researchers have criticized the seemingly unsystematic and arbitrary addition in DSM-5 of "bizarre new illnesses" such as Excoriation Disorder (skin picking), Major Depressive Disorder 2 weeks after a bereavement, or Somatic Symptom Disorder when one is adjudged 'too upset' when told of a cancer diagnosis [14]. New diagnoses have mostly arisen when a few influential insiders have decided that a new category would be clinically meaningful and handy, and have lobbied for its inclusion [76].

Unlike mental disorders, CPPs must be 'natural kinds' of things in the world [77, 78] with a defined essence [79], that delineates a category else they revert, like mental disorders, to being merely dimensional variants of normality $[80,81]$. Such a capitulation, in which we merely choose to call something a mental disorder or a CPP when it has gone far enough to bother us, is a surrender to the opposite, postmodern extreme $[82,83]$ in which problems may be explained by a "medical narrative" no more or less legitimately than by a learning theory-based narrative, or by "socio-political, spiritual or paranormal explanations" [14]. When a conceptual overreach leads to the abandonment of the scientific method 
altogether, the need for a 'paradigm shift' is urgently indicated.

It is generally recognized in all fields of scientific endeavour that it is preferable that concepts be essentialist rather than undefined or arbitrary [61], and categorical rather than dimensional [84] or merely nominal [81]. For example, it is epistemologically and clinically much more useful if disorders can be conceptualized in terms of pathological processes rather than being solely descriptive [81]. After a century of successful, progressive research and practice in clinical psychology, we are more than confident that CPPs exist in the real world [8], and are qualitatively different from normality, but depend on a client's, a therapist's, or society's evaluation. That is, that CPPs are a form of 'harmful dysfunction' [75] where the harm is a judgement, but the dysfunction is objective [85].

Though CPPs are almost universally and intuitively regarded as qualitatively different from normality, much theoretically important research has focussed on dimensional constructs and their relationships with (even barely valid) categories such as mental disorders. This has occurred because each approach (dimensional or categorical) has its advantages in different contexts [86]. When testing hypotheses, dimensional measures in research retain more information than categories, especially for phenomena that are distributed fairly continuously, and with unclear boundaries [70].

Categories are also highly dependent on appropriate cutpoints. We know that cutpoints for most mental disorders are fuzzy and somewhat arbitrary. This is why they are barely categorical. And this is also why most dimensional models of psychopathology focus on the personality disorders [87]. They have even more 'fuzzy boundaries' than the other mental disorders.

Hence, recognising the problems that DSM-5 and ICD10 have had with arbitrary thresholds, large category overlaps, and low clinical utility, the new ICD-11 has adopted a dimensional approach to personality disorder classification with 5 trait qualifiers: Negative Affectivity, Detachment, Dissociality, Disinhibition, and Anankastia [88]. Whereas DSM-5 and ICD-10 require a quota of criteria to be met (e.g. 5 of 9 ) to define a disorder, ICD-11 diagnoses Personality Disorder via global evaluation of personality functioning, where the clinician may specify 5 evidencebased trait dimensions that contribute to the unique expression of personality disturbance.

It has been claimed that WHO's ICD-11 is less entirely based on tradition and authority than the DSM [48] as it is more empirically derived, in that dimensional approaches correspond better to the observed data than do purely categorical ones [47]. Continuous (dimensional) measures of psychopathology have been found to increase both the reliability and the validity of assessments over discrete (categorical) measures [70]. Subsequent to this, Reed, Sharan et al. [89] found the reliability of ICD11 's guidelines to be superior to that previously reported for equivalent ICD-10 guidelines, and Reed, Keeley, et al. [90] found clinicians rated the clinical utility of ICD-11's diagnostic guidelines very positively with regard to ease of use, but still poorly for treatment selection.

Note that the dimensions of personality functions here refer to processes rather than static traits or features, and therefore this assessment of functioning more closely approximates a functional analysis than a diagnostic checklist. And it therefore can potentially more closely lead to therapeutic conclusions [88]. "[T]reatment should target what the Personality Disorder does to the patient (i.e., severity), as we cannot change what it is (i.e., traits)."

These changes of direction embodied in the soon to be implemented ICD-11 are a response to the recognition that psychotherapeutic interventions are often transdiagnostic [91]. However, they offer only a clinically useful dimensional overlay to a categorical 'mental disorder' conceptualisation - not a paradigm shift. "Advances in psychiatric research in general, and progress in nosological science in particular, will continue to be iterative....but no evidence has suggested that genetic or other biological information will lead to a paradigm shift in diagnostic classification in the immediate future" ([91] p.7).

However, clinicians and clinical researchers generally require a categorical approach [86] because they need to constantly decide whether to treat or not, whether to hospitalise or not, or which drug or psychotherapy to apply, or not. ICD-11, as well as DSM- 5 must be predominantly categorical for administrative and treatment selection purposes. Such decisions are categorical, even if the data underlying them is dimensional [48].

For our purposes, the cutpoints and criteria for the determination of the presence of a CPP must be clearer, better validated, and more essentialist than those for the diagnosis of mental disorders. Dimensional measures give us indications as to the statistical significance of a relationship or an outcome, but categorical approaches tell us more about their clinical significance - whether a qualitative difference has been created or detected, or merely a possibly-trivial change in one psychometric score.

The usual structure of research projects in this field has been to explore the relationships between dimensional constructs and factors, such as 'anxiety sensitivity', and categorical problems, such as generalised anxiety disorder (GAD) [92] even though GAD as a construct has poor validity, dubious reliability, and an arbitrary cutpoint. Hence, it has been noted that the cycle of progress that is meant to occur between dimensional research in psychiatry and clinical diagnostic accuracy has not eventuated $[86,93]$.

When dimensional measures are used in research on mental disorders, the richer data has provided even more evidence that DSM diagnoses correlate poorly with 
these measures, and that they better predict certain psychological processes than psychopathological conditions. For example, Melville et al. [94] found that problem behaviours, rated or scored dimensionally, among adults with intellectual disabilities, loaded in a factor analysis within an emotion dysregulation/problem behaviour dimension, not within depressive, anxiety, organic, or psychosis dimensions or factors.

Similarly, when the relationship between the dimensional construct 'dispositional negativity' and adverse outcomes such as 'emotional disorders' is studied [95], a "dynamic cascade of processes" - presumably amenable to functional analysis - is uncovered; not a simple relationship with one or two diagnosed mental disorders. Further, when dimensional psychopathology measures are factor analysed across a population, a strong general psychopathology factor emerges. Carragher et al. [96] concluded from this that transdiagnostic treatment approaches are indicated and warranted, and the domain of psychopathology should be restructured in an empirically-based manner, as has recently commenced through the HiTOP consortium [69].

So dimensional approaches to CPPs or to mental disorders can be very valuable, especially in research. But it would be preferable that any psychological-level alternative to the categorical diagnosis of mental disorders be a more evidence-based and essentialist categorical conception of CPPs.

Therefore, any new conception of CPPs must, by contrast with DSM's mental disorders, be theory-rich, evidence-based, problematic-by-judgement, real-bynature (essentialist), categorical (qualitatively distinct from normality) according to only one or two reliable and valid criteria, and must recognise various conceptual kinds of psychological problem.

\section{Treatment-relevant case formulation versus nominative diagnosis}

With further regard to the DSM system's natural taxonomic inadequacies for clinical psychologists, because the vast majority of psychologists seek to intervene at a psychological level (i.e. in situations, thoughts, feelings, and behaviours), they are much more interested in developing a process- or functional- or mechanismfocused case formulation than a symptom-derived diagnosis. Clinical practice is predominantly theory-based rather than manual-prescriptive [53].

Whereas psychiatric practice is more and more dominated by the process of deriving DSM diagnoses, [32, 97], an examination of the UK's Generic Professional Practice Guidelines for psychologists, or the APS's College of Clinical Psychologists Course Approval Guidelines, shows that "training programs for clinical psychologists emphasize formulation rather than diagnosis" ([52] (p.448). Formulation is fundamental to clinical psychology in the same way that diagnosis is fundamental to psychiatry [51], and DSM diagnosis is often irrelevant to psychological practice [20, 54].

Among the advantages of the case formulation approach identified by the BPS's Division of Clinical Psychology [17, 98] are much greater treatment-relevance, strengthening of the therapeutic alliance, normalization of problems, providing a sense of hope, reducing blame, and increasing collaboration and empathy.

With regard to treatment-relevance and clinical utility, even for psychiatrists the DSM "describes a collection of disorders, not an integrated system of psychopathology" ([31] (p.147). Many existing diagnoses encompass multiple pathological processes [33]. DSM's search for reliability of diagnosis at the cost of theoretical integration and validity [84] plus its high rates of comorbidity, high frequency of "Other Specified/Unspecified" (previously "Not Otherwise Specified") diagnoses, and divergent and overlapping criteria sets make for little guidance in choice of treatments [25].

But especially for clinical psychologists, who are more concerned with psychological-level case formulation, in most cases a DSM diagnosis tells one little about etiology, course, choice of treatment, or treatment response [52, 99-103]. "Identifying a disorder by its symptoms does not translate into understanding it. Clinicians need some heuristic concept of its nature, grasped in terms of cause or mechanism" ([104] p.1845).

A clinical psychologist basing treatment on a DSM diagnosis in place of a case formulation is like a dietician assessing the adequacy of a person's diet by taking a height measurement, instead of interviewing the person. Height measurement is a much more reliable, consistent, brief, and precise process, but far too much validity and treatment relevance are lost.

Therefore, the new conception and taxonomy of CPPs must be formulation-relevant and treatment-relevant, and not just a listing of surface-symptom-defined diagnoses.

\section{Processes or mechanisms versus topographical description}

Tucker [97] admitted that, by contrast with the rest of modern medicine, in psychiatry "we are still doing pattern recognition" (p.159). This approach falls down when the same pattern or topography can be established by diverse processes, or when different topographies can come from the same process [35]. These phenomena have come to be known as the problems of multifinality and divergent trajectories [105]. Multifinality [106] refers to how one general transdiagnostic risk factor or process can result in several different disorders, as when stress [107] can contribute to the development of several different CPPs involving anxiety, depression, or alcohol abuse. Divergent trajectories occur when more proximal or 
moderating variables, such as attentional biases, result in OCD in one person, but a sleep disorder in another [105].

The DSM system has ignored these issues and focused on final symptoms and their topography, saying nothing about mechanisms. We need to comprehend psychopathological disorders "not simply by their outward show but by the causal processes and generative mechanisms known to provoke them" ([104] p.1855).

Major problems such as treatment irrelevance and excessive unexplained comorbidities have resulted [28-30]. In the clinical psychological literature these comorbidities, such as between Major Depressive Disorder, Generalized Anxiety Disorder, and Dysthymia [108], are assumed to reflect the many similarities of inputs, symptoms, and processes among the various models of particular CPPs.

All of these factors have led to the recent development of transdiagnostic models of psychopathology [109-111] which seek to identify fundamental processes underlying multiple, often comorbid, psychopathologies [105, 112].

Mechanisms across the disorders, such as negative attentional bias [113], experiential avoidance [114], safety behaviours, or rumination [115] have been studied, and transdiagnostic treatment programs that target these processes rather than individual diagnoses have then been developed $[4,109,116,117]$. This naturally follows the finding that more than half of patients who present with depressive disorders also have elevated comorbid anxiety symptoms, and that, when psychotherapy for depression is undertaken, anxiety can be significantly ameliorated [118]. Very few studies have examined this issue because the literature is strictly structured around individual psychiatric disorders [118].

Current transdiagnostic approaches circumvent the problem of the plethora of manualized treatment programs for a growing number of specific diagnoses [119], so that the training of therapists and development of treatment packages can be more parsimonious [4].

The taxonomic arm of this empirically-based transdiagnostic movement - the Hierarchical Taxonomy Of Psychopathology (HiTOP) consortium - grew out of the psychological study of individual differences [120]. Its rich vein of studies [121-123] establishing an alternative dimensional organization of psychopathology helps to overcome such problems with traditional nosologies as the issue of arbitrary thresholds and subsequent loss of information, ensuing reliability problems, diagnostic heterogeneity, theoretically disruptive high comorbidities [120], and exclusion of undiagnosable 'subthreshold' people with serious CPPs $[49,69,124]$.

The emergent HiTOP dimensions form a hierarchy with five levels (symptoms, syndromes, subfactors, etc.), and can thus help explain why disorders from different classes respond to the same treatment (e.g. social anxiety responding to antidepressants) [49]. In this way it is a critical part of the transdiagnostic movement.

But the HiTOP hierarchical dimensional models of classification, though guided by research [120] are still the result of a consensus among the consortium [49], require interpretation by human experts [48], and the approach suffers from all the problems of a dimensional taxonomy. It has not, to date, been used clinically, as the consortium has yet to develop meaningful cut-off points for pathology [49]. It can still only offer a dimensional elaboration, based on symptom measurements, on top of a categorical 'disorder' model [48], because it still does not implicate proximal causes for, and the 'essence' of, CPPs. It is a descriptive phenotypic model, and does not directly incorporate etiology and underlying mechanisms [49]. It shares many of the same constructs with the categorical model frameworks [120] such as a focus on 'mental disorders'.

For example, when Nolen-Hoeksema and Watkins [105] have suggested ways to explain multifinality and divergent trajectories in terms of distal, proximal, and moderating causes or risk factors (p. 592), they have done so via a flow chart resulting in (DSM-type) 'Disorder A', 'Disorder B', and 'Disorder C'. Despite emphasising that we need more focus on the precise mechanisms involved (p.591), the transdiagnostic movement still regards an Anxiety Disorder as the same CPP whether it has arisen through a mechanism of avoidance or of rumination. The necessary 'paradigm shift' would see these two situations as different CPPs.

As psychological interventions increasingly target mechanisms, such as specific cognitive dysfunctions, rather than symptom-based mental disorders, a new comprehensive conceptual framework to assemble the results of psychotherapy research will be required [125].. The transdiagnostic movement has not to date offered a 'paradigm shift'; only a useful extra (dimensional) layer, such as allowing for variables such as 'neuroticism' or 'extraversion' in treatment selection [119], on a categorical 'mental disorder' conceptual system.

But also, these transdiagnostic processes and properties are dimensional responses to problems with the categorical assumptions of DSM [64]. The assumption is that the heterogeneous disorders in DSM are made up of dysfunctional versions of processes that vary along continua in the general population $[45,126]$. For example, attentional bias toward negative information is common in people without [113]. Within the transdiagnostic movement to date, such a bias cannot be regarded as essential or diagnostic. So there remain problems of cut-off points, a quality distinction between different problems rather than a quantity distinction, and the very definition or essence of CPPs. A categorical conception of CPPs is preferable $[61,84,86]$. It is much preferable 
that CPPs, unlike mental disorders, display an essence that they be more than just 'worse than normal'.

It has been argued that dimensional data can lead to actionable 'diagnoses' in medicine [69], so why not in clinical psychology? For example diagnoses are determined, and treatments initiated, from blood pressure measurements and fasting glucose levels using indicative ranges of scores. However, even in medicine, this is regarded as second best. It is much preferable to uncover some clear, qualitatively distinct pathology such as an infection or a lesion, than to find that a score looks too high or too low. Is it better to treat every adult person under a height of $4{ }^{\prime} 6$ " with growth hormone, or to reserve this treatment for people who are not producing their own growth hormone?

Hence, the new conception of CPPs will focus on mechanisms and processes, not states or conditions. But beyond the current transdiagnostic movement, it will regard the operation of these processes as essential, definitive, and 'diagnostic'. Thus a categorical conception will emerge, not a merely dimensional one.

\section{Some CPPs are clearly not mental disorders}

In examining what clinical psychologists actually address in research and practice, a stark example of the nonequivalence of CPPs and mental disorders can be found in the fact that clinical psychologists address relationship, marital, and family problems using the exact same assessment and treatment models as for, for example, anxiety or depression problems. Such interpersonal situations clearly cannot be conceptualised as internal mental disorders, and so DSM has relegated "relational pathology" to a terse footnoted ' $\mathrm{V}$ '-code listing, an omission long lamented $[127,128]$. As a bizarre and unfortunate consequence, when a clinical psychologist sees a couple or family in the Australian Medicare system they are not eligible for a fee rebate unless one attending party has been given a mental disorder diagnosis by the referring medical practitioner and is being treated for this. 'No blame' relationship therapy will not be rebated.

A similarly bizarre and unfortunate result of the conceptual medicalization of CPPs arises with parenting problems. Patterson [129] has described how parentchild interactions frequently directly reinforce deviant behaviour, and he has outlined the role of parent-child discipline practices in the development and maintenance of aggressive behaviour in children. These insights led to the development of the most empirically supported treatment for such problems - Parent Management Training [130]. But, again, to be eligible for a rebate in Australia, not only must the child have a diagnosis of, for example, Conduct Disorder, but the child must attend each consultation. The assumption is that the problem resides within the child, as would a lesion or infection, and so the mental disorder must be in attendance for treatment to be conferred.

However, perhaps the largest class of CPPs effectively addressed by clinicians, but barely researched because they are not 'mental disorders', lies in the third to half of all people who seek clinical psychological help but cannot be given a clear diagnosis because their problems do not fit criteria and categories neatly [131]. They may be 'subthreshold' [132], or 'subclinical' [133], or situationspecific (such as being evidenced only at work). High levels of distress commonly occur in the absence of a diagnosable condition [134], as when one or two symptoms occur very strongly, but three or more are required for a diagnosis [135]. Should clinical psychologists turn away people presenting with such CPPs because they do not have a diagnosed mental disorder?

Therefore, not all CPPs are internal mental disorders detectable and definable by a certain intensity of symptom presentation. They are more likely to be particular sorts of psychological-level processes, which can occur between people as well as within them.

\section{Social consequences of seeing all CPPs as mental disorders}

Promotion of the disease model of CPPs has often occurred in an attempt to ameliorate the serious stigma consequent upon the 'moral failing', sinfulness, or demonic possession models of CPPs [136, 137]. The medical model has been advanced as a simple solution to the "brain or blame" dilemma or the "chemistry or character" dichotomy as to whether a person's mental suffering is real, or they should be told to pull themselves together [14].

Clinicians' models affect the community's beliefs and hence sympathetic or stigmatizing attitudes [8]. Psychiatry was aware of this when it promoted the disease model of alcoholism in an attempt to reduce stigma and punitive responses, and increase treatment takeup and compliance [138]. Support groups have used the fact that the concept of mental illness has been arbitrarily defined to agitate for problems such as depression or alcohol dependence to be regarded as diseases, hoping to reduce stigmatization and increase service or research funding [85].

However, in many areas this strategy has backfired, and the personal and social consequences of a psychopathological label have proven to be negative, fatalistic, adverse, and stigmatizing [139]. The "disease like any other" campaigns to convince the public that mental disorders are non-volitional biological illnesses for which sufferers do not deserve blame and discrimination have been "an unequivocal failure in reducing stigma" ([12] p.852). For example, with regard to attitudes to depression and schizophrenia, Schomerus et al. [140] found 
that (a) belief in the biomedical model has increased, (b) acceptance of medical treatment has increased, but (c) attitudes toward people with mental disorders has not improved.

A diagnosis of a mental disorder can often be a cause of disempowerment and social exclusion [141], and may label the person rather than the problem [142]. A diagnosis of mental illness is known to negatively affect selfidentity, attract stigma [143], result in a negative prognosis, and engender isolation $[144,145]$. People who believe that mental distress is a kind of biological illness are more likely to see psychiatric patients as dangerous and unpredictable [146, 147]. They may blame less, but will fear and avoid patients more [148], and will assume a worse prognosis $[147,149]$.

Such deleterious consequences are exacerbated by DSM's assertion that all of the following are examples of the one kind of thing. They are all equally 'mental disorders': Mild Tobacco Use Disorder, Schizophrenia, Female Orgasmic Disorder, Delirium, Restless Legs Syndrome, Alzheimer's Disease, a Spider Phobia, and Opioid Intoxication. Admitting to sadness 2 weeks after one's spouse has died can put one in the same class, conceptually, as a paranoid schizophrenic, a smoker, a person suffering a panic disorder, or a violent psychopath.

These consequences of problem assessment and problem formulation are not inevitable. It has been claimed that a psychological case formulation or functional analysis approach both avoids the problem of stigmatization [52] and the abdication of responsibility [150] of a mental disorder diagnosis. This provides further reason that the new conception of CPPs needs to be psychologicallevel and formulation-based.

\section{Research on CPPs versus mental disorders}

Although in practice clinical psychologists formulate much more than they diagnose, almost all research in the discipline ignores this fact. To be considered methodologically sound, and hence to qualify for funding, almost all psychotherapy research must be undertaken with formally diagnosed subjects with the intention of 'curing' them of their mental disorders by removing their symptoms. However in real-world clinical practice case formulation guides treatment, which targets psychological processes, not symptom profiles. Treatment outcome measured by "escape from diagnosis" is in this light arbitrary, misleading, and inadequate.

Research trials have typically treated highly selected groups with a single diagnosis, while in clinical practice patients have many comorbidities and atypical symptom profiles [54, 119]. Clinicians are more likely to apply several interventions, and will base this on the individual case formulation they have developed, on the assumption that each technique is targeting something different. When experimental subjects are merely diagnosed and then randomly allocated to comparative treatment groups, they will have an undetermined distribution of relevant underlying mechanisms [151]. A 'package' approach ignores basic psychological science and the individual needs of individual clients, is atheoretical, and alienates research from clinical practice [151].

Important comparative studies on various CBTs for depression, such as cognitive therapy $(\mathrm{CT})$ versus behavioural activation (e.g. [152, 153]), or for anxiety problems, such as exposure therapy (ET) versus CT (e.g. $[154,155])$, have not been able to find consistent differences between comparative treatments [151]. Michelson et al. [156], for example, were unable to separate the benefits of cognitive, behavioural, and psychophysiological treatments for agoraphobia, though all three were superior to a wait-list control. This is unsurprising, though, when subjects are DSM-diagnosed and then randomly allocated to groups, as though they all have the same CPP. It assumes a diagnosis-to-treatment-selection link. This is an example of theory governing the nature of research. However, the medical model of DSM is so entrenched that many researchers would not even see this difference ([21] p.157).

"There are undoubtedly many functionally distinct subtypes of patients currently mixed together in popular diagnostic systems" ([102] p.971). For example, agoraphobics may have a classically conditioned fear of separation, or a fear of panic attacks. Further, this latter fear may in turn be of medical catastrophes or of social embarrassment [151]. Over a quarter century ago, Wolpe $[157,158]$ warned that such neglect of individual differences in the dysfunctional processes that occur within a diagnostic group puts us in danger of making a mockery out of group treatment outcome research.

A major motivation of the HiTOP consortium has been the fact that randomized controlled trials (RCTs) rarely show superiority among thoughtfully conceived treatment packages [120], and that research has found that many interventions can be beneficial with a host of problems regarded as distinct categorically [118].

This problem has been thoroughly outlined by Smith, McCarthy, and Zapolski [159], who have pointed out that assessing the effect of CT versus ET on a DSMdefined 'Depression' group is an example of assessing the relationship of a construct or variable with another multidimensional construct or measure (such as PTSD or Neuroticism) which has multiple (diagnostic) criteria. The resultant composite correlation will be an average of the correlations with each of the dimensions or criteria, each of which could correlate quite weakly with the others. 
The power of RCTs is seriously compromised when the groups that subjects are randomized into are vaguely or spuriously defined. "With heterogeneous treatment effects, the ATE [average treatment effect] is only as good as the study sample from which it was obtained" [160]. This is why researchers have begun to focus on transdiagnostic mechanisms of intervention [161]. "Diagnostic heterogeneity compels the clinician to go beyond the assigned diagnosis and generate individual-level formulations that are not codified in the diagnostic scheme" ([120] p.6).

It will be of much greater benefit when we are able to assemble research results into clinical guidelines not on 'the treatment of Depression' or 'of Bulimia Nervosa', but on psychological interventions with CPPs A and B, defined by mechanisms, which may cross diagnoses or differ within a diagnosis. For example, we know that targeting specific mediating cognitive processes in a social phobia is more effective than standardized generic cognitive-behavioural treatment [162], because the mental disorder 'Social Anxiety Disorder' can encompass a number of (mechanism-defined) CPPs.

\section{Conclusions}

A new conception of CPPs must therefore be: (a) A psychological-level one (i.e. involving cognitions, behaviours, emotions, and situations); (b) Psychologically theoretically rich and evidence-based; not a postmodern 'categories-by-convention-only' model. It must define an essence. If it comprises a 'harmful dysfunction' (Wakefield, 1992), then its harmfulness must be a matter of subjective judgement, but its dysfunction must be defined objectively; And according to only one or two criteria, not a hodgepodge of them; (c) Categorical, rather than merely dimensional; (d) Encompassing of all problems currently appropriately and successfully addressed by clinical psychologists; not merely diagnosed mental disorders; And (e) better at avoiding the stigma and responsibility-confusion problems which have been exacerbated rather than ameliorated by the disease model.

\section{Seeking the essence of clinical psychological problems}

By examining what clinical psychologists actually research and address in their clinical practice, we have come quite close to uncovering the essence of CPPs. Thus far we are clearer about what constitute 'psychological problems'.

\section{'Psychological problems'}

Clinical psychology, like forensic psychology or clinical neuropsychology, is an applied remedial discipline. To remedy is to rectify or make good, to cure or heal, to put right or restore, or to counteract or remove.
Therefore the new taxonomy will list problems - negative 'states of affairs' that are undesired, aversive, inappropriate, maladaptive, or dysfunctional. This loose listing of potential criteria is an indication that the ultimate judgement as to what constitutes a 'problem' will inevitably be largely subjective and value-laden, based on 'presenting problem' (the client's standpoint), social norms (society's standpoint), or psychometric measures (the therapist's standpoint). Unlike mental disorders, CPPs will not be of their nature problematic. They will have to be deemed problematic.

CPPs are by definition at a psychological level of analysis. That is, at the level of stimuli, cognitions, emotions, and behaviour. Therefore, the new taxonomy to be proposed will not be a listing of biological dysfunctions or of problems faced by communities, cities, nations, or the human species. Sociologists and anthropologists can work at such taxonomies.

It may include, however, problems at an interpersonal, couple, or family level. Clinical psychology has studied these, and does provide remediation at this level. In this respect CPPs are further distinguished from mental disorders, because the biological level of analysis, which DSM's mental disorders aspire to, is conceptually as well as practically discordant with relationship problems. Very few would recommend that we medicate a faltering relationship.

\section{'Clinical Psychological Problems'}

But what makes psychological problems clinical? That is, what makes them warrant interventive clinical psychological therapy? If a taxonomy of CPPs is to be treatment-relevant, then not only will different CPPs imply different treatments, but the very definition of a CPP will include a criterion of being treatment-worthy.

To feel sad is a negative psychological-level state of affairs - a psychological problem. But it can also be an appropriate, constructive, natural, 'healthy', adaptive, or functional problem to have, as in normal grieving. What determines when this state of affairs warrants intervention? When does it become clinical? Is it simply a matter of degree - a dimensional criterion? Or can it be categorical - a qualitative criterion?

Table 1 lists a number of negative but overwhelmingly spontaneously-remitting psychological-level problems, and CPPs (using current DSM mental disorder labels) with similar topographies or phenomenologies. How can we tell whether a person is obsessed by food because he is being careful with his diet this week, rather than because he has an 'eating disorder'? How can we distinguish a 'huff' between a husband and wife, from a relationship problem that requires intervention? One answer would be 'Time will tell'. But what occurs differently during this time? 
Table 1 Negative situations or reactions and their corresponding 'psychopathological' counterparts.'Symptoms' do not distinguish or define the 'pathology'. So what does?

\begin{tabular}{ll}
\hline Psychological Problems & Clinical Psychological Problems \\
\hline Grief reaction & Depression \\
Acute stress reactions & Post-traumatic stress disorder \\
Binge & Bulimic disorder \\
Anxious state & Anxiety disorder \\
Episode of substance abuse & Addiction \\
Misbehavior & Conduct disorder \\
Argument & Relationship problem \\
Diet & Anorexic disorder \\
Pain & Chronic pain syndrome \\
Tantrum & Impulse control disorder \\
Worry over health & Somatoform disorder \\
Fussiness & OCD \\
\hline
\end{tabular}

Studies of the extremely common negative situations or reactions listed in Table 1 ('psychological problems') show that they generally do not self-perpetuate and they tend to ease without interventive therapy. This has been found to be the case in most grief reactions $[163,164]$, acute stress reactions [165], the spontaneous remission of many psychological problems [166], and in all our daily experience.

What is the essential difference between a person in a depressed state, perhaps experiencing a grief reaction, and a person whose depressed state justifies, and can benefit from, interventive therapy? A person experiencing a natural, healthy grief reaction following a bereavement (a psychological-level problem, but not a CPP) can present phenomenologically quite severely. She may tick most of a symptom list. This cannot therefore define a $\mathrm{CPP}$, as she may well be following a natural course toward resolution (as the majority of bereaved people do). That is, the process occurring - not the 'symptoms' or their severity - will determine whether a CPP is present and intervention is warranted. This criterion can be categorical: Either an undesired, harmful, or dysfunctional process is occurring, or it is not.

Therefore, the essence of CPPs lies in a mechanism or process of maintenance, which can be discovered through functional analysis or case formulation, and which then requires and justifies ('clinical') psychological-level intervention or therapy to disrupt it.

\section{A mechanism or process...}

The overwhelming majority of people who experience the grief of loss emerge from this process without clinical intervention $[167,168]$. But symptoms do not distinguish or predict who will recover within a reasonable timeframe and who will not. DSM-5 [10] merely states that a Bereavement reaction or a "normative stress reaction" may be called an Adjustment Disorder "when the magnitude of the distress...exceeds what normally would be expected" (p.289) - a dimensional, not a categorical criterion - and a diagnosis of Major Depressive Disorder may only be given after 2 weeks after the loss ([10] p.160) - a highly controversial pronouncement [169].

The most comprehensive and influential evidencebased grief theories are the Dual-Process Model of Stroebe and Schut [170] and Worden's Task-Based Model [171]. These both describe processes that are natural and usually successful. Could complicated grief [172], prolonged grief [168, 173], or Major Depression be best defined and distinguished by a different process? Especially one that is cyclic and self-perpetuating rather than linear and progressive. This would explain why routine intervention for bereavement is not generally recommended, and "may interfere with 'natural' grieving processes" ([174] p.140).

\section{....Of maintenance...}

What is the necessary and sufficient condition that can distinguish a person simply experiencing anxiety from a person with a clinical anxiety-related problem who can benefit from interventive therapy? A comparison between an acute stress reaction and Posttraumatic Stress Disorder (PTSD) can illustrate this difference.

Around $60 \%$ of men and $50 \%$ of women will experience one or more significantly traumatic events in their lives $[175,176]$. Extreme distress is common in the immediate aftermath of a traumatic event [177]. In the first weeks after a traumatic event most people experience recurring distress in response to reminders, and re-live the event in memories, dreams, and flashbacks $[178,179]$.

Acute stress reactions are unpleasant, and so they are a 'psychological problem'. However, they generally fade over time [180] and most people will recover spontaneously with some support [177]. A majority of people who experience a traumatic event do not develop PTSD [181]. The lifetime prevalence of PTSD is approximately 8\% 176].

Because DSM diagnosis is symptom-profile-based, and many people experience severe symptoms in the immediate aftermath of trauma, DSM has defined an interim disorder - Acute Stress Disorder (ASD). However, around the same proportion of trauma survivors with or without ASD symptoms - with other symptoms or with sub-clinical symptoms - can go on to develop PTSD [182]. Also, trauma can lead to other classes of problem, especially depression [183]. So the experience of a traumatic event and the immediate presence of ASD or PTSD-like symptoms are poor predictors of PTSD [165]. Better predictors as to whether initial learned alarms become a persistent problem and "snowball" ([180] p.15] into full-blown PTSD include accessibility of social 
support, and the trauma survivor's coping style [184]. A key feature of the latter is whether it is predominantly an avoidant coping style [185-187], whether this be cognitive or behavioural avoidance [188, 189].

It is no coincidence that two of the most recommended treatment elements for PTSD are prolonged in vivo exposure therapy and imaginal exposure to flashbacks [190]. With regard to in vivo exposure, Wirtz and Harrell [191] found that either spontaneous or planned exposure to triggers associated with a trauma soon after the event reduced the likelihood of experiencing persisting distress. Such exposure seems to be how distress dissipates for the majority of trauma survivors [180]. Similarly, cognitive avoidance is undesirable when cognitive confrontation is necessary, as with obsessive or PTSD flashback problems [192].

Such a summation of this research shows that the development of PTSD from an acute stress reaction is a function of maintenance processes that can occur in the aftermath of a trauma. If, on the other hand, treatment is directed at symptoms, then this can interfere with adaptive processes. Critical Incident Stress Debriefing (CISD) and other such proactive interventive treatments administered early in an acute stress reaction have been found to be ineffective, or even counterproductive, in the prevention of PTSD [177, 193-197], just as routine intervention after a bereavement is contraindicated [174].

This critical maintenance criterion for CPPs holds that psychological problems such as sadness or anxiety (problematic emotions), preoccupations or obsessions (problematic cognitions), or classroom disruptive behaviour or frequent handwashing (problematic behaviours) (see Fig. 1) will, being aversive, tend to resolve, diminish, habituate, or extinguish if not maintained. This process of maintenance, if it occurs at a psychological level, and so is amenable to psychological-level intervention, is then what 'causes' and defines a CPP. "Self-perpetuating vicious circles" have been found to explain the persistence of "symptoms" not only in grief and bereavement and in PTSD, but also in anxiety states, panic syndromes, obsessive problems, and depression [163].

Therefore, the essence of a CPP lies in some form of psychological-level maintenance process. Inasmuch as a treatment needs to address the 'true cause' of a CPP, the relevant maintenance process should also indicate appropriate therapeutic intervention. (See Appendix A concerning confusion over addressing the 'true cause', historical etiology, and underlying mechanism etiology).

\section{....Discovered through functional analysis or case formulation}

While many medical diagnoses point to underlying biochemical or neurological mechanisms, few psychopathological ones do [23-25]. Neither do they indicate particular psychological-level mechanisms [34, 35]. Hence, clinical psychologists rarely find such diagnoses useful.

Instead, clinical psychologists will develop a case formulation through a functional analysis of presenting problematic behaviours, cognitions, emotions, and situations or stimuli $[139,198]$. The case formulation or conceptualisation "will explain the origins of the problem, account for the maintenance of the current problem, and make predictions about prognosis, [and] prescribe treatment options" ([199] pp. 89-90).

Clinical psychologists, in practice, do very little diagnosing, but much case formulation [51, 52, 200]. According to Persons [201], the purpose of such a formulation is always to direct treatment. "The case formulation links the patient's data on the one hand with the treatment plan on the other" ([199] p. 89). Whereas in psychiatry the interview may be mainly guided by the DSM classification process, in clinical psychology case formulation is an experimental hypothesis-driven procedure in pursuit of a "clinical theory" (the problem formulation) that guides the therapy process [202].

Early forms of CBT tied to DSM's diagnostic categories produced manualized protocols ('a pill for an ill').

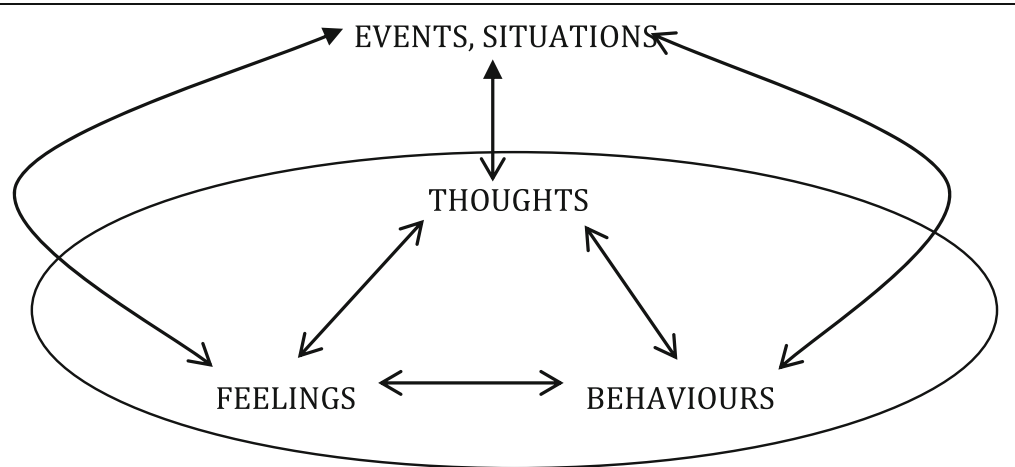

Fig. 1 The Generic CBT Model, illustrating the essentialism of cyclic maintaining causal processes ${ }^{\mathrm{a}}$. The open arrows represent normal material sequential causal pathways. The filled arrows represent A effectively altering B. This, and specific and general examples of each causal arrow, and the involvement of drug therapies, is fully described in [219]. 
However, the case formulation approach has led much more to tailored, individualized treatments based on idiosyncratic, but evidence-based, case conceptualizations [54]. The Division of Clinical Psychology's position statement on functional psychiatric diagnoses recommended the promotion of the use of psychological formulation rather than traditional psychiatric diagnosis ([17] p. 9).

\section{For example, CBT case formulation}

Case formulations in clinical psychology are developed within many alternative theoretical orientations. Any new conception, and hence taxonomy, of CPPs will need to accommodate all evidence-based models of CPPs. It will need to be, in that sense, a meta-theory.

However, for present purposes, in our search for an essence to CPPs, the process of case formulation within behaviour therapy and within CBT will be examined initially.

The 'functional analytic clinical case models' of behaviour therapy were developed as a clear and parsimonious way to organize the variables and relationships in a functional analysis ([139] pp.31-33). These vector-graphic representations of variables and their functional relationships, involving causal arrows connecting boxed or enclosed variable labels, have proven to be an effective way to communicate behavioural case conceptualizations, and are subsequently a guide to treatment decisions [203].

This technique was adopted for individual CBT case conceptualization as well, and hence their generalized form - CBT models of psychopathology - are also often presented visually as vector diagrams [139] with cognitive, emotional, behavioural, and environmental/situational elements connected by causal arrows, which can mean "leads to", "causes", "allows", "determines", "increases", "affects", "enables", "is a result of", or "is dependent on" ([139] p., 32, [32] p., 459). Textbooks in CBT are replete with these models. Because CBT case formulations and subsequent treatments focus heavily on maintenance processes rather than historical etiological causes, almost all such models incorporate feedback loops, made evident by the arrows in their diagrammatic representation.

The first highly influential such evidence-based model of a CPP, incorporating a full feedback loop or 'vicious circle', was Clark's panic cycle [204]. Many others have been developed since directly from the empirical research, and describing a wide range of problems, including general emotional distress ([135] p. 44), PTSD ([205] p. 321), 180 (pp. 10-11)], panic disorder ([206] p. 109), worry (p. 79), general anxiety ([207] p., 53, [208] p., 9), bulimia ([209] p. 19), anorexia (p. 21), social phobia ([210] p. 72), depression ([211] p.178, [212] p. 98)], OCD ([213] p., 127, [214] p., 80, [215]), hypochondriasis ([216] p. 261), and health anxiety $([217,218]$, p., 370$)$.
All of these models can be represented by the generic CBT model presented in Fig. 1. This is the most advanced, evidence-based candidate for "an alternative, universal theory of what maintains and exacerbates psychological distress" ([4] p. 8). The model incorporates such diverse psychological phenomena as operant conditioning, classical conditioning, cognitive mediation, expectancy effects, cognitive dissonance effects, psychoeducation, multimodal therapies, and transdiagnostic therapies [219-221].

Note that Fig. 1 is of its nature a cyclic maintenance model, not an historical etiological model. (See Appendix A.) It does not specifically include a unidirectional input causal arrow representing historical etiological factors. In CBT, historical etiology is of sufficient interest to be included in early assessment, and in a case formulation. But it rarely determines treatment, which will be primarily dependent on identification of elements in the maintaining causal processes [222]. Historical precipitants are less treatment-relevant, less universal, and suffer from the problems of multifinality and divergent trajectories [105].

\section{The network model}

In parallel with the transdiagnostic movement, an alternative conceptualization of mental disorders has emerged that does not see them as latent underlying disease entities revealed by discrete symptom sets, or as labels for arbitrarily targeted sets of symptoms. McGrath [223] has observed that theoretical terms in psychology, such as "depression", may often refer to a constellation of variables, rather than to a single latent structure.

Partly in order to explain DSM's excessive comorbidity rates, such as between Major Depressive Disorder and Generalized Anxiety Disorder, Cramer et al. [27] have proposed a Theory of Complex Networks, in which disorders are viewed as "networks that consist of symptoms and causal relations between them" (p. 138). In the complex network approach "disorders are conceptualized as systems of causally connected symptoms rather than as effects of a latent disorder" ([224] p.93). The symptoms then do not measure a disorder, they are part of it. A disorder is thus conceptualized as "a cluster of directly related symptoms" ([27] p.140). An example could be: Chronic stress $\rightarrow$ depressed mood $\rightarrow$ self-reproach $\rightarrow$ insomnia $\rightarrow$ fatigue $\rightarrow$ concentration problems ([224] p.96). Comorbidity is then a result of direct bidirectional relations between the symptoms of each disorder, for example the sleep disturbance and fatigue of MDD and the chronic worrying and difficulty concentrating of GAD ([27] p. 139).

This entirely new way to conceptualize CPPs is already heavily research-based (e.g. [225]) engenders more useful clinical research $[224,226]$, thoroughly explains comorbidity patterns $[27,225,227]$, and is naturally compatible 
with a transdiagnostic process model of mental disorders [79], such as that of Nolen-Hoeksema and Watkins [105].

Also, psychopathology networks, unlike mental disorders, can extend beyond the individual. Reciprocal interactions can occur between people, as when a child's sleeping problems produces parental sleep problems; both feed into behaviour problems, which then increase parental stress, and which does no good at all for the parents' management of the child's sleep problem ([224] p.104). A notion of CPPs derived through a complex network model can incorporate interpersonal psychological or relationship problems.

And networks - like diagrammatic case formulations - imply intervention points. The 'centrality' of a symptom in a network refers to how causally connected and hence clinically relevant it is. It is recommended that one target in therapy the most central symptoms [228].

However, the network model does not as yet offer us a new conceptualization - a new "essence" of the common psychological disorders [79]. Until very recently, it has continued to view MDD and GAD as autonomous entities able to receive and send out causal effects, and has assumed the "illusion of one-way causality" between biological and behavioural levels of the system. This merely adds a dimensional layer onto a categorical disease model of CPPs. And has thus presented us with 'fuzzy boundaries' between diagnostic categories. Cramer et al. ([27] p.183) have asserted that the difference in the network model between "disorder" and "no disorder" is how many symptoms are "on", or how severe they are. There are two criteria here. One would be better. And they are both dimensional criteria. How many symptoms need to be "on" to call a problem a CPP? And how severe do they have to be? No essence to mental disorders is stipulated.

This falling short (until very recently) of offering a new conceptualization of CPPs is attributable to the network approach's assumption that mental disorders and psychopathology arise from or result from the causal interplay between psychopathological symptoms [227]. So in this model causal networks are explanatory and ubiquitous, but not yet essence-defining.

Borsboom [229] and Borsboom et al. [230] have come closer to such an essence when postulating that a comprehensive model of psychopathology could be developed if it is recognised that the networks' biological, psychological, and societal mechanisms and causal relations can be sufficiently strong to generate a level of feedback that renders them self-sustaining in feedback loops that become 'stuck in a disorder state'. Borsboom [229] describes this as a "general feature" of mental disorders. If, instead, this were to be regarded as a universal, essential, and definitive feature of psychopathology, then a true 'paradigm shift' would be complete.
Another major problem for clinicians with the network model to date is its complexity. Not only are there disagreements over the reliability of the general and theoretical results of network analysis methods (see [231] versus [232]), but in specific analyses, Cramer et al. ([27] p.180) admit that when etiology is conceptualized in terms of the development of a network over time, this can lead to enormous complexity, depends on numerous vulnerabilities, and will vary greatly from one individual to another. Belzung et al. [233] have pointed out that the discernment of therapeutic targets under the network model could be extraordinarily difficult. We are still missing a simplifying essence to CPPs.

What if, in "defining our disorders at the level of property clusters under-girded by dysfunctional but selfsustaining mechanisms" ([40] p.1149), we focus on the "self-sustaining mechanisms" (the systems or processes) rather than the "property clusters" (the topographic symptoms)? After all, "causal meaningful relations between symptoms....are the very stuff of which mental disorders are made" ([224] p.96).

\section{The need for a 'linchpin'}

So both the transdiagnostic movement and the network model have moved focus from symptom measurement and diagnosis to the case formulation of problemmaintaining processes. But no replacement conception and subsequent problem taxonomy or functional classification system has yet ensued [34].

The major drawback of psychological-level case formulation of CPPs when contrasted with the diagnosis of mental disorders is that functional analyses or case formulations can be complex, vague, and idiographic ([35] p.1153). Case formulation is relatively unreliable [51]. For example, both Persons et al. [234] and Mumma and Smith [235] have found good agreement among therapists in identifying presenting problems, but poor agreement in identifying hypothesized underlying cognitive mechanisms. Eells et al. [236] reviewed intake evaluations at an outpatient psychiatric clinic. They found 95\% included descriptive information, but only $43 \%$ proposed an inferred psychological mechanism.

Superimposing a transdiagnostic dimensional model over a categorical diagnostic nosology (e.g. [237]) merely adds to this complexity. Functional analysis has remained "neither specific nor replicable" ([99] p.381). But a taxonomy of all possible problematic cognitions, and behaviours, and emotions, and stimuli or triggers would be unwieldy and arbitrary, barely explanatory, and would not define CPPs according to one or two discernible criteria.

Therefore, what is required is some form of simplifying "linchpin" [238] which could guide and standardise case formulation, aid communicability through standardisation 
of nomenclature, and ultimately define the presence and essence of CPPs.

\section{The essence: problem-maintaining circles (PMCs)}

Assembling the criteria developed thus far, the items to be listed in the new taxonomy of CPPs must be: Problems, formulated at a psychological level, that warrant therapeutic intervention, and rest on an empirically-supported, theory-rich model, which parsimoniously and categorically defines processes or mechanisms that exist in the real world, are causally maintaining and hence treatmentrelevant, simplify complexity, and aid in case formulation. It is also desirable that such listed CPPs can generate and organize treatment-relevant research, are codifiable, will minimize stigma, include relationship problems, and recognize and distinguish various 'kinds' of problem.

So, having loosed ourselves from the conceptual manacles of the mental disorder model of CPPs, we now find the requirements imposed upon our new conception to be much more exclusive and demanding. But one notion can satisfy all of the above criteria.....

\section{All clinical psychological problems are caused by PMCs}

It is the claim of this Proposal that the smallest, simplest 'unit of psychological pathology' which fulfils all of the above criteria is the functioning of a problem-maintaining circle (PMC) of psychological-level causal elements, several illustrations of which are presented in Fig. 2 in the form of vector diagrams. This is the simplest, most basic unit of a CPP expressed in evidence-based graphic models of psychopathology, in the generic CBT model of Fig. 1, and in the case formulations of most scientistpractitioner or practitioner-scholar clinicians. It is the 'linch-pin'. This causally cyclic (maintaining) mechanism depicts the essential difference between a negative psychological-level state of affairs (a psychological problem), and a state of affairs requiring interventive treatment - a clinical psychological problem (CPP) (see Table 1). A CPP is then any undesired, self-maintaining, psychological-level causal cycle that involves people's thoughts, feelings, behaviour, and situations.

Until a full PMC forms, a negative psychological-level state of affairs may be a problem, but it is not a 'clinical' problem warranting formal therapy. It can be expected to pass, as normal, successful coping mechanisms are employed. As soon as it becomes self-perpetuating via a PMC, such as the use of an unsuccessful coping technique (avoidance comes to mind, or rumination, or ...), then intervention is justified. The identified mechanism of perpetuation or maintenance will then indicate points of intervention, and hence particular therapies.

To be upset (e.g. an acute stress reaction) is negative and psychological, so it is a 'psychological problem', but this does not warrant referral, formulation, and
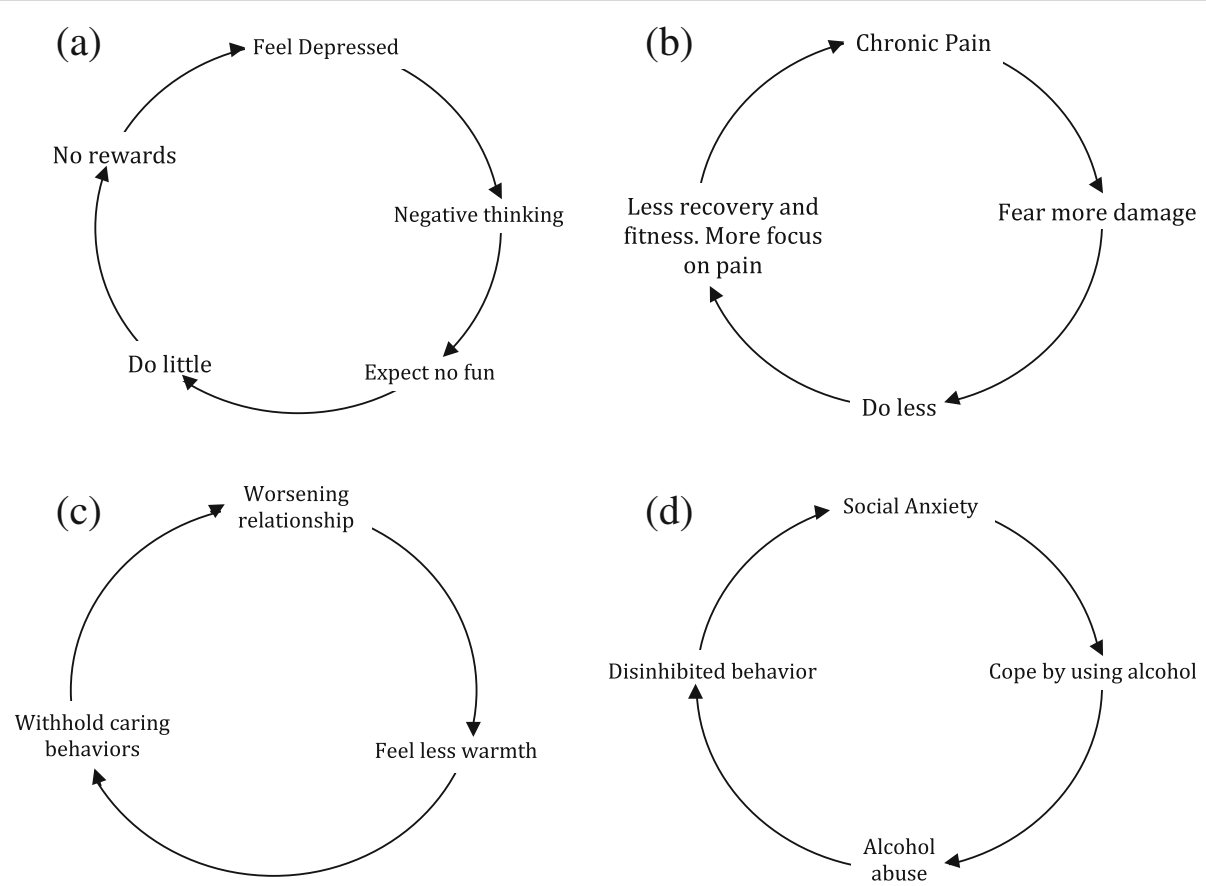

Fig. 2 Examples of PMCs defining CPPS. Each is research-derived, generalized, explanatory, treatment-relevant, can be detected by a comprehensive psychological assessment and functional analysis, and be presented in a communicable codified case formulation. (See Appendix B for a proposed listing and coding system of such PMCs.) They exemplify PMCs within CPPs involving (a) depression, (b) a chronic pain problem, (c) a relationship problem, and (d) a 'comorbid' social anxiety problem with a causally interrelated alcohol abuse problem 
therapeutic intervention, until it persists or becomes self-maintaining (e.g. PTSD) through a process or mechanism which, when identified, can also indicate which treatment to apply. This mechanism then is the essence of, and defines, the CPP.

The simplest expression of a PMC would be a bidirectional causal relationship between two features within one element of the tripartite model of Fig. 1 (cognitions, emotions, or behaviours), as when Thought A leads to Thought B, which leads to Thought A ("I am a worthless person" $\rightarrow$ "For example, I've failed that exam" $\rightarrow$ "See, I am a worthless person"), or between two features in different elements of the tripartite model, as when Thought A leads to Feeling X, which leads to Thought A ("Life is awful" $\rightarrow$ sadness $\rightarrow$ "Life is awful").

Since people are innately complex, many PMCs will involve several elements of Fig. 1 before a full selfperpetuating causal circle is completed, such as: Feel depressed $\rightarrow$ Do little $\rightarrow$ Few achievements in life $\rightarrow$ Low confidence and self-esteem $\rightarrow$ Do less $\rightarrow$ Few pleasures in life $\rightarrow$ Feel depressed.

\section{PMC formation, and the marginal relevance of historic etiology (See Appendix A)}

If a full PMC does not form, the psychological problem (for it is still aversive, and occurring at a psychological level) will likely resolve, remit, dissolve, or be processed. For example, Bill and Mary have a screaming row. Tomorrow, Bill apologizes and life goes on. If, however, Bill wakes tomorrow still angry, ignores Mary over breakfast, she sees and resents this, there is no intimacy all week, both blame the other, her respect for him decreases, etc., then one or more PMCs have formed, and the situation qualifies as a relationship CPP which would benefit from therapeutic intervention, as it is unlikely to spontaneously remit soon.

The description of a forming PMC can start at any element of Fig. 1. For example, if someone begins to withdraw from people (a Behaviour) - whatever the reason (physical disability, poverty, illness, depressive mood, taking on a job as a lighthouse keeper, etc.) - this can lead to a socially impoverished lifestyle (Events, Situations), which can result in lowered social confidence and self-esteem, and more caution, or even catastrophizing, about people (Thoughts), which can lead to more anxiety in social contacts (Feelings), which naturally results in more withdrawal (Behaviour). Which point in this sequence is identified as the 'start' of the circle is somewhat arbitrary and often marginally relevant by the time therapy is sought. The initial precipitant is often no longer critical. But the behaviours, situations, thoughts, or feelings that produce a maintaining cycle are.

Generally, historical etiology of a CPP is identified in the 'Events, Situations' element. Common examples of such include past traumas, parenting styles, recent traumas, and stress accumulation. However, it is just as possible that 'Feelings' or 'Behaviours' or 'Thoughts' could "go wrong" first. Examples could include a spontaneous panic attack (a Feeling) leading to Panic Disorder, PTSD that forms from an acute stress reaction due to coping by avoidance (a Behaviour), or health anxiety that becomes problematic due to catastrophic thinking (a Thought). What "went wrong" first may be important in the prevention of CPPs, but is largely irrelevant once PMCs have formed. This is the reason that all recommended evidence-based therapies happen to focus on problem maintainers rather than require analysis of presumed distant historical precipitants.

\section{PMCs and treatment-relevance}

The elements in a PMC can be specific, such as a particular thought, or general, as in an abiding attitude [219]. They can be cognitive, behavioural, emotional, or situational. Therefore each formulated PMC can implicate a number of intervention points at several levels.

For example, the 'Feel depressed' PMC of Fig. 2(a) may suggest interventions such as a form of cognitive therapy (to attack the "Negative thinking" element) or behavioural activation (to attack the "Do little" element) or a change in circumstances (ditto re "No rewards"). The relationship PMC of Fig. 2(c) could lead to a homework exercise of writing a list of the best features of your partner (to affect the "Feel less warmth" element), or a commitment to hug your partner three times a day (to affect "Withhold caring behaviours").

By definition, a PMC formulation that explains the maintenance of a CPP must indicate at least one intervention point, and hence imply a known therapeutic procedure which targets this, or at least invite research into effective interventions at such a point.

\section{PMCs within and between 'mental disorders'}

A PMC taxonomy is clearly transdiagnostic. Some PMCs occur within the symptom network [27] of what has been traditionally regarded as a single separate distinguishable disorder, such as Depression, or Panic Disorder, or Substance Abuse. Examples of these can be found in Fig. 2(a and b), and in the numerous vector diagrams of the CBT models of psychopathology listed earlier.

However, many empirically discovered PMCs occur between the symptom clusters of traditionally distinguished disorders. They involve 'bridge symptoms', in network terms. Figure 2(d) is an example. It illustrates a 'comorbidity' explanation for Social Anxiety and Alcohol Abuse. Such PMCs explain DSM's high comorbidity incidences. A comprehensive PMC taxonomy would include such recognized evidence-based PMCs. Among 
the most researched are the mutual relationships between anxiety and depression problems [239]. However, new ones are constantly being discovered or confirmed, such as a bidirectional association between depression and sexual dysfunction [240], between cigarette smoking and panic disorders [241], or between pain problems and PTSD [242], and precise causal links need to be uncovered in the search for therapeutic intervention points.

The voluminous and clinically valuable literature uncovering causal relationships between symptoms [27], whether they be within a cluster regarded by DSM as a single disorder, or between such disorders, currently has no place to be assembled and coordinated. Comorbidities are currently seen as theoretically disruptive. An evidence-based taxonomy of PMCs will bring together this highly therapeutically relevant information in a clinically useful way.

\section{Fast and slow PMCs}

The PMC model of CPPs replaces the seven-or-more criteria for the existence of a mental disorder found in DSM, with one criterion: Has a psychological-level PMC formed? The nearest DSM criterion to this is duration of the problem. However, this is an inadequate criterion because the complexity of life means that some PMCs can form and warrant intervention in days, and some do not cement for months, even years. Sleep problems deserving of psychological-level intervention can form in days. If a person has a disrupted night for any reason, and then is kept awake by the anxious anticipation of another terrible night, a PMC has formed in 2-3 nights that can perpetuate or even spiral. Intervention to break this PMC may be warranted and successful even on Night 2.

On the other hand, the cognitive, affective, and behavioural changes that are expected, and possibly necessary, after the death of one's lifelong spouse may persist for a year or longer, during which time a clinician would be loath to interfere lest the bereaved's natural coping and recovery processes be disrupted ([174] p.140). This is due to the prolonged natural course of such grief reactions. Counseling support may be offered, but this is supportive and guiding rather than interventive of some 'pathology'. It will understandably take a long time to be sure of, and intervene with, any PMC explaining the onset of a prolonged grieving/depression CPP.

\section{The need for a new taxonomy of clinical psychological problems}

When the subject matter of a scientific discipline has been determined and defined, the process of study will begin descriptively, with systematic observation and listings [4]. From such activity universal principles, processes, and concepts are developed which comprise the discipline's scientific theories. A core element of such theories has been the listings and classifications of their subject matter - the taxonomies - that each scientific enterprise has developed.

"A reliable system of classification is important for the advancement of a clinical science" ([243] p. 386) because this process within the scientific method subsequently becomes circular, such that discovered general principles, processes, and concepts then guide further observations, research, experiment, and classification ([5] p. 13). What is listed and classified - the subject matter of the discipline - is therefore critical to the advancement of the scientific enterprise, because all subsequent research is dependent upon it. We do not observe and experiment in a vacuum. What we seek and how we incorporate what we find is dependent upon our frame of reference. "Experiment is planned action in which every step is guided by theory" ([244] p. 280). "Our observational experiences are...impregnated with theories" (p. 111).

Therefore, the development of the most appropriate taxonomy of CPPs is essential for progress in clinical psychology to enable research to produce general laws and rules, to provide a common language for the reliable assessment of problems, to simplify communication, to codify problems for third-party payers, to enable relevant reliable research conclusions, to suggest problem causes, to optimize and tailor treatments, as well as to develop new ones, to inform and ease the minds of sufferers, and to organize access to services, benefits, or support groups $[14,53]$. All of these functions have been performed for clinical psychology - though generally poorly - by psychiatry's DSM, which has dominated in the administrative functions of billing and coding, insurance and service funding models, clinical communication, and research funding and approvals [101, 245].

But it has done this poorly because, though greater specificity and description of symptoms at a phenomenological level has at least given us a common language that can be applied with reasonably good interrater reliability [21, 246, 247], becoming more atheoretical to achieve greater reliability in diagnosis has sacrificed almost all claims to validity [248]. Psychiatry has tried to become tighter, stricter, and more precise at identifying made-up mental disorders.

While the British DCP has been calling for a conceptual paradigm shift [17], across the Atlantic the American Psychological Association has formally expressed concerns that DSM-5's (re)development is not benefiting psychological treatment outcomes [11], and the president of the Association for Behavioral and Cognitive Therapies has advocated for a new cognitive-behavioural classification system for mental disorders [53]. (Note that, until a conceptual paradigm shift occurs, this proposal is still about "mental disorders" rather than CPPs.) 
The current state of psychological science has been compared to that of physics 200-300 years ago, in that, despite voluminous research over the past 60 or so years, it is still plagued by theoretical disunity, which is largely a consequence of the non-standardized use of terms by researchers and clinicians in their theoretical orientation silos [249]. This disunity is reflected in an absence of clinical psychology's own general taxonomy of CPPs.

As with clinical psychology's own conception of CPPs, the nature of its own taxonomy of CPPs can be derived from: (1) DSM's inadequacies; And (2) clinical psychologists' natural taxonomic focus and categories.

With regard to (1) DSM's taxonomic inadequacies for clinical psychology, all of the problems with DSM's conception of CPPs apply to its taxonomy. Its items (mental disorders) are conceptually biologically based, not psychological-level processes. They have no psychological (or even biological) essence, and so definition and classification are only descriptive, not explanatory, and diagnosis is minimally treatment-indicative.

Due to its medical model basis, DSM diagnosis does not even tell us when to intervene medically (e.g. pharmacologically) and when to intervene at a psychological level (e.g. with a CBT), let alone whether to intervene psychologically by first addressing a person's situation, and/or their thinking patterns, and/or their behaviour, and /or their feelings states.

Furthermore, several types of CPPs (e.g. marital problems) are not included. The stigma of a DSM diagnosis of 'mental illness' is barely less than that of ascribing moral weakness or sinfulness or demonic possession. And research based on DSM categories has not been able to find systematic or explanatory links between psychosocial treatments and problem types. These are the problems that a new PMC-based classification of CPPs must, and can, overcome.

Further, a new taxonomy of CPPs, based on a new conception of CPPs, must be: (a) an aid to case formulation, case conceptualization, or the functional analysis of behaviour; (b) a listing of processes or mechanisms, rather than states, conditions, or diseases; (c) a recognition of and distinction between various conceptual kinds of psychological problem, such as between 'clinical' versus 'normal,' psychopathological' versus 'psychological', 'organically-based' versus 'functional', etc. (d) relevant to (psychological-level) treatment choice; and (e) usable in place of diagnostic groupings in research on psychotherapy outcomes.

With regard to (2) clinical psychologists' natural taxonomic focus and categories:

\section{Kinds of psychological problems}

As the currently proposed taxonomy is to be radically treatment-relevant, both the categories within the taxonomy (which treatment for which CPP?) and the borders of the taxonomy (when is treatment warranted? when is it 'clinical'?) must be defined by this criterion. Thus far CPPs have been distinguished from other psychological problems (Table 1) by the presence or operation of treatment-warranting PMCs. Other (transitory) psychological problems, such as an anxious state or a crisis situation, may benefit from support, guidance, or information, as this can facilitate an expected adjustment/recovery process. But interventive (clinical) therapy is not indicated. The PMC model provides a useful distinction between the concepts of supportive "counselling" and interventive "therapy".

\section{Psychopathological problems}

But within the class of intervention-justifying, PMCinvolving CPPs, surely there are different 'kinds' of CPPs, including ones for which psychological-level, PMCbreaking treatments are not the first-line, or best practice, or most empirically supported interventions. For example, are some problems still best regarded as 'mental disorders'? These are likely to be problems primarily maintained by circumstances other than psychologicallevel PMCs, such as biochemical-level problems.

A clear candidate for a distinction between differing kinds of CPPs, that has theoretical and treatmentrelevant underpinnings, lies in the distinction between predominantly organic (neurological-level) and predominantly functional (psychological-level) problems. "The current classification systems are less controversial for conditions with an identified biological aetiology such as in the fields of neuropsychology, dementias, and moderate to severe learning disability" ([17] p.2).

Because biochemistry underlies all psychological activity (all of Fig. 1) [14], it has been assumed that biological layers or levels of analysis have intrinsic causal priority [79]; that genes affect brain activity, which affects behaviour. This assumption underlies the medical model of CPPs. But we know from innumerable examples that the causal flow goes in all directions between these levels.

For example, changes in brain PET scan images of sufferers of OCD show the same effects after successful CBT treatment as after successful pharmacotherapy [250, 251]. Increases in testosterone levels can increase aggressive behaviour, but inducing aggressive behaviour can increase testosterone levels [252]. Childhood emotional maltreatment has been associated with a decrease in medial prefrontal cortex volume years later [253]. But treatment of these effects in adulthood is still best undertaken at a psychological level, which presumably will alter the underlying neurology.

We are dealing here simply with different levels of analysis. So far, brain scans have told us little new clinically and nothing new philosophically [56]. All 
subsequent pronouncements have thus far been "neurologisms" [254], meaninglessly adding "neuro-' to whatever term is being claimed to be more 'real' than before we imaged the concurrent neural activity. Human thought and action unfold at a number of explanatory levels and we can gather different insights at different levels of analysis ([56] p.xvii). "The view that human experience and behavior can best be explained from the predominant or even exclusive perspective of the brain" is an example of "neurocentrism" ([56] p.xix).

It is the clinical utility of the candidate levels of analysis and of intervention that should determine whether a problem is best regarded as a 'psychopathological problem' or a CPP. Therefore, are there problems that are better considered - either in therapeutic terms or in explanatory-mechanism terms - as essentially organicallybased rather than entirely PMC-driven? Haslam [62] has argued that there are. He cites as examples autism and schizotypal personality. These problems may be blurred by threshold effects and multiple causal factors, but they have relatively non-arbitrary boundaries, and underlying causal mechanisms have been proposed that are not entirely psychological-level.

Further examples of problems that are difficult to account for in a purely symptom-network model [27] include schizophrenia in remission, ADHD when behaviour is controlled in a specific environment, and delusional disorder. Hood and Lovett [255] argue that the underlying disorder in these cases is latent or silent. Rubinsten and Henik [256] have added mathematical disorder, reading disorder/dyslexia, and developmental dyscalculia as almost certainly examples of the expression of underlying brain dysfunctions.

From a treatment perspective, some problems respond better to pharmacotherapy than to psychotherapy. For example, APA's [257] practice guidelines for the treatment of patients with schizophrenia are predominantly pharmacological. Medication is considered firstline treatment for schizophrenia [258], and concurrent psychosocial interventions are "almost always offered adjunctively to pharmacotherapy" ([134] p.292). This treatment-relevance confers some clinical utility upon the DSM diagnosis of schizophrenic disorders [243].

Therefore, although CBT-based family therapy and stress management have been found to reduce the incidence of readmission with schizophrenia [134, 259-262], neither of these approaches is expected to 'cure' the condition, or to optimally manage the problem when used exclusively, whereas psychotherapy with most anxiety or depression problems is. CBT is not first-line therapy for schizophrenia because more than psychological-level PMCs seem to be operating.

Therefore, PMC theory seeks to distinguish problems best regarded as psychological-level, or psychopathological, or psychiatric, or neurological, or sociological, and so on, and promotes concept definition and an appropriate problem taxonomy at each relevant level.

Another consequence is that the common language of 'mental health' services is anticipated to remain that of 'mental disorders'. This conception has dominated for a long time, and is arguably the most appropriate for a substantial portion of people's problems. PMC theory and its conception of CPPs is likely to remain an $a d d$ itional, concordant, and complementary body of concepts and therapy-relevant taxonomy.

\section{Type I, II, and III psychological problems}

Table 2 distinguishes three types or kinds of psychological problem within the PMC model. Type I psychological problems are aversive, undesired, negative, or dysfunctional psychological-level states of affairs that are very common, expected, normal, transitional, 'non-

Table 2 'Kinds' of psychological problems

\begin{tabular}{|c|c|c|}
\hline TYPE I General Psychological Problems & TYPE II Clinical Psychological Problems (CPPs) & $\begin{array}{l}\text { TYPE III Psychopathological Problems } \\
\text { (Mental Disorders) }\end{array}$ \\
\hline Normal 'linear' psychological reactions. & Persistent undesired psychological reactions. & Diagnosable psychopathologic conditions. \\
\hline No PMCs identified (yet?). & PMCs have formed. & $\begin{array}{l}\text { Breaking psychological PMCs may not be enough. } \\
\text { Biological PMCs may also be operating. }\end{array}$ \\
\hline Refer for counseling? & Refer for clinical psychological therapy. & Refer for psychiatric (and psychological?) therapy. \\
\hline $\begin{array}{l}\text { Grief reactions } \\
\text { - Acute stress disorder } \\
\text { - Anxiety states } \\
\text { - Life event stress } \\
\text { - Life transitions } \\
\text { - Adjustment disorders } \\
\text { - Personality difficulty } \\
\text { - Burnout }\end{array}$ & $\begin{array}{l}\text { - Anxiety disorders (Panic disorder, Specific phobias, ...) } \\
\text { - Depression } \\
\text { - Feeding or eating disorders } \\
\text { - Obsessive-Compulsive or Related Disorders } \\
\text { - Sexual problems } \\
\text { - Posttraumatic Stress Disorders } \\
\text { - Relationship problems } \\
\text { - Substance abuse/dependence } \\
\text { - Gambling disorder } \\
\text { - Sleep problems } \\
\text { - Personality disorders } \\
\text { - Prolonged Grief Disorder }\end{array}$ & $\begin{array}{l}\text { - Schizophrenia } \\
\text { - Schizoaffective disorder } \\
\text { - Bipolar affective disorder } \\
\text { - Dementia } \\
\text { - Delusional disorder } \\
\text { - Autism disorder } \\
\text { - Seasonal affective disorder } \\
\text { - Post-viral depression } \\
\text { - 'Third-day blues' } \\
\text { - Sleep-wake disorders }\end{array}$ \\
\hline
\end{tabular}


clinical', probably adaptive, have not formed PMCs, and may benefit from counseling-level support. Type II psychological problems are CPPs in which one or more PMCs are operating. They are unlikely to remit spontaneously, or transition easily, and clinical intervention is warranted and likely to be effective. Type III psychological problems are those negative psychological-level states of affairs in which the breaking of psychologicallevel PMCs is unlikely to be sufficient to achieve normality, and neurophysiological-level mechanisms are likely to be the primary maintainers to the problem. They may be regarded as essentially 'psychopathological'.

It must be noted that these two criteria - likely mechanism and first-line therapy - are not always consistent with each other. There are some Type III conditions for which the current best practice treatments are psychotherapies, simply due to the lack of advancement in the biochemical or neuropsychological understanding and control of the problem. Examples.

would include DSM's Premenstrual Dysphoric Disorder, which, though assumed to have an organic basis, is better ameliorated by CBT [263-265] than by pharmacotherapy [266, 267]. Menopausal symptoms have the same standing [268, 269], as does Chronic Fatigue Syndrome [270-272], and the research and treatment guidelines are not consistent with regard to ADHD [273-275].

It is quite possible that problems will move between Types II and III classifications as psychological-level or neural-level underlying mechanisms are discovered and new treatments are developed. Again, though, these two criteria are separable. For example, neural mechanisms underlying OCD and PTSD are being uncovered [276278], but subsequent treatments have not ensued, and for now both problems are clearly in the Type II category on the level-of-treatment criterion. This may be different in 30 years' time.

\section{Kinds of (type II) clinical psychological problems}

The DSM, being based on an atheoretical pragmatic model, both poorly defines the limits of its taxonomy (What is a mental disorder and what is not?), and arbitrarily categorizes its contents (What are the 'kinds' of mental disorder?). The lack of a defining essence to mental disorders means that, unlike the PMC-based distinction between mundane psychological problems (Type I) and CPPs (Type II), the DSM does not tell us when to treat.

But within its taxonomy DSM also regards all of the following as examples of the one 'kind' of thing: A bereavement reaction, a spider phobia, OCD, antisocial personality disorder, schizophrenia, autism, and frontal lobe syndrome. They are all equally 'mental disorders'. This absence of theoretical discrimination spreads the stigma of mental illness widely, gives no guide to subsequent treatment, or to research direction, and results in unending disagreement as to kinds, categories, or classes of problems, meaning that each iteration, up to and including DSM-5, has announced major reorganizations of internal structure.

The ultimate goal of classification is its connection with treatment $[21,35,279]$. The proposed content of the new taxonomy of CPPs - indeed the very definition and essence of CPPs (i.e. PMCs) - has been determined primarily by the criterion of treatment relevance.

However, treatment relevance is only one element of the clinical utility of a taxonomic listing. Clinicians will use a taxonomy of CPPs for other purposes such as input to case formulation, for administrative, insurance, or legalistic purposes, to assist in communicating clinical information, the use of categories in clinical practice, and predicting future clinical management needs ([280] p.947). A taxonomy will be judged according to its manageability, practicality, and conformance with logical and intuitive conceptualization [280].

If classification within the taxonomy were to be according solely to specific treatment implications, this would result in categories such as "Problems treatable by exposure therapy" or "CPPs for which thought stopping is frequently a useful adjunct". Such categories would be large, unwieldy, highly overlapping, and counterintuitive. Also, this would be a reversion to the medical model 'pill for an ill' or 'Condition $\mathrm{X}$ therefore Treatment $Y$ ' approach, rather than increasing the rate, reliability, and communicability of case formulation and subsequent tailored treatment programs.

The phenomena of divergent trajectories and multifinality [105] mean that several evidence-based therapies may be helpful for a particular problem situation, and that a particular therapy may be effective for several differing problems. This is entirely consistent with the success of transdiagnostic therapy programs and with PMC theory, in which each PMC has several elements - all possible intervention points - and any one element (e.g. hypervigilance) can feature in several different PMCs. The elements within a PMC can be specific (e.g. a thought) or general (e.g. an attitude). They can be cognitive, behavioural, emotional, or situational. Therefore each PMC can implicate a number of intervention points at several levels. The number of identified transdiagnostic processes implicating different transdiagnostic therapies is already very large [4]. And some modes of intervention, such as attention-based treatments, have been found to be useful for a large number of CPPs [281]. Grouping by specific intervention is not intuitive for clinicians [282, 283].

DSM has been criticized for ignoring the spontaneous consensus models of the clinical community [284]. 
Extensive studies of the conceptual taxonomies of clinicians have found that they do not match those of DSM or of ICD-10 in structure [282, 283, 285-289].

The 'folk taxonomies' of eclectic clinicians are quite consistent across theoretical orientations and professions $[288,289]$, and are guided by several aspects of clinical utility [280]. Usually included are mood disorders (excluding bipolar and cyclothymic), anxiety disorders, substance abuse disorders, eating disorders, externalizing childhood disorders, developmental disabilities, schizophrenia, and dependent and paranoid personality disorders [283]. Experienced clinicians group together anorexia nervosa and bulimia nervosa, as well as substance dependence with substance abuse, conduct disorder with oppositional defiant disorder, panic disorder with phobias and GAD, and mental retardation with autism [285]. Psychiatrists have been found to prefer fewer categories, and with flexible (ICD-11-type) guidance rather than strict criteria-based diagnoses [287]. The same preference for (ICD-11-type) flexible guidelines over (DSM-5-like) strict criteria has been found among psychologists [290]. Such classifications are generally pragmatic, and based on 'presenting problem'.

When PMCs are grouped under presenting problems such as 'Depression' or 'Anger problems' [219], then homework sheets covering possibly relevant PMCs can be easily selected and tailored. "Some nomothetic conceptual overlay is necessary as an initial guide to the more indepth process of individual functional analysis because it defines the domain of interest" ([99] p.380). Such categories are not formal diagnoses. Denman [291] has pointed out that case formulations will inevitably have 'diagnostic elements' in them, but not in a mental disorder/DSM sense. For example, "the problem is 'marital in nature" is a form of diagnosis and a useful label when formulating a person's problems to determine treatment [52], so 'marital' or 'relationship' categories of PMCs would be clinically useful, but not as de facto DSM diagnoses.

The HiTOP consortium [49] has revealed a transdiagnostic, empirically-derived, hierarchical dimensional model of classification of mental disorders. Its broader dimensions ('spectra', such as an internalizing dimension) correspond in PMC theory to PMCs that operate among many, or even most, of our clientele. For example: 'Develop a CPP $\rightarrow$ Feel out of control $\rightarrow$ Lowered selfefficacy feelings $\rightarrow$ CPP is perpetuated.' ([219] p.30.) Such broad, generic, near-universal PMCs deserve a category to themselves, as do the broader HiTOP dimensions. (This category is labelled "PMCs 11.y.z Any Psychological Problem" in Table 3 in Appendix B.)

Therefore, it is proposed that PMCs be grouped in the new CPP taxonomy for clinical utility under generallyaccepted well-understood presenting problem headings such as 'Anxiety problems', 'Depression', 'Relationship problems', 'Eating/Weight Problems', and 'Substance abuse/dependence'.

\section{A proposed classification and coding system}

A nascent micro classification system of PMCs is already in clinical use and is taught in several postgraduate clinical programs [220, 221]. However, this listing is ad hoc, idiosyncratic, and unlikely in such an embryonic state to provide codings that would achieve broad acceptance. An effort by teams of clinicians and researchers corresponding to some meaningful fraction of the effort devoted to the development of the DSMs, is required to construct a systematic, exhaustive, and evidence-based taxonomy of CPPs in the form of distinct, identifiable PMCs. "One can only speculate how fruitful psychological research would prove to be were decades of the financial and head-space resources devoted to biological research...available to psychology" ([292] p.738).

However, in the interim, a proposed classification and coding system is presented in Appendix B. It proposes three-level numerical coding of the format "PMC x.y.z" in which ' $x$ ' codes represent presenting problems (e.g. depression), including Type III psychological problems (e.g. schizophrenia), and 'Interactive clinical psychological problems', currently labelled as 'comorbid conditions' (e.g. chronic pain \& anxiety). Then ' $y$ ' codes represent the major classes of problematic underlying maintaining mechanisms commonly identified in several presenting problems (e.g. hypervigilance). And ' $z$ ' codes represent specific evidence-based mechanisms which imply specific treatment approaches (e.g. behavioural avoidance).

For example, the PMCs illustrated in Fig. 2 would code as: (a) PMC 2.2.3 (A depression problem maintained by negative thinking, which may benefit from Cognitive Therapy.) (b) PMC 6.1.3 (A persistent pain problem maintained by behavioural avoidance.) (c) PMC 3.5.3 (A relationship problem reinforced by ongoing mutual dislike/disrespect.) and (d) PMC 13.6.1 (An interactive problem in which coping by using alcohol maintains a tendency to social anxiety.)

Such a framework can systematically summarize and stimulate the currently disparate streams of research on assessment, case formulation, and therapeutic intervention in clinical psychology. For example, instead of assessing the efficacy of a particular Cognitive Therapy package in helping a diagnostically uniform (but psychologically heterogeneous) sample of sad people, subjects could be selected based upon identification, through an assessment and case formulation, of the presence or functioning of PMC 2.2.3 above. Such would be infinitely more logical, and just as methodologically sound in a randomized controlled trial. 


\section{The PMC model is a metatheory}

CBT's substantial evidence base, and its inherent emphasis on here-and-now case formulations and therapeutic disruption of problem maintainers, make it a natural fit for the PMC model of CPPs. For example, the dimensional models being developed by the HiTOP consortium are particularly compatible with CBT approaches [120]. They are both evidence-based, empirically inclined, and transdiagnostic, and HiTOP's dimensions are very useful in CBT formulations [159].

However PMC theory is not specific to a CBT view of the world. The Complex Network Model of CPPs, which PMC theory has grown from, "does not involve the acceptance of any particular theory about psychopathology" ([224] p.96). HiTOP's models are "theoretically agnostic" [120]. Theorists and practitioners from a range of orientations have identified and targeted 'vicious circles' or 'vicious cycles' as a core feature of their conception of CPPs. Only the nature and level of causal elements within their formulated PMCs vary.

For example, the movement toward integration of models of psychotherapy [293, 294], has frequently pointed to cyclic processes between internal (psychodynamic) states and external (cognitive-behavioral) events [295]. Reciprocal, cyclic, self-perpetuating processes have a "pervasive role" in psychoanalytic, cognitive-behavioral, systemic, and experiential models of psychopathology [296].

Within the psychodynamic model the type of problem or disorder can be gleaned by content, but the presence of a disorder can be determined by "cyclic psychodynamics" [297-299]. Narcissistic personality disorder, for example, can be understood purely intrapsychically and/ or as an environmentally-maintained disposition in which "what makes them continue to feel bad is how they go about trying to feel better" ([295] p.52). Shortterm existential interventions have been explained as ways to break vicious circles of emotion [300].

Family systems theorists have long emphasised cyclical formulations with psychodynamic elements [301]. Indeed they have promoted this focus on 'circular causal loops' in problem formulations - as opposed to linear psychodynamic cause and effect explanations - as a 'new epistemology' [302].

Nor is defining the essence of a clinical problem in terms of vicious circles or PMCs particular to clinical psychology. It has been proposed or enacted within forensic psychology [303, 304], organizational psychology [305], and crossculturally [306]. Much of medicine describes vicious circles of organic pathology (fever, organ failure, etc.) treated by intervening in biochemical PMCs. For example, many neurodegenerative diseases are now understood in terms of "cascades" of "proteinopathies" within or affecting neurons [307].
Therefore, theorists and researchers from many theoretical orientations are able to contribute, and to utilize, the new taxonomy, only providing that the focus is on problem maintenance, and the relevant PMCs and implied treatments are evidence-based.

\section{Advantages of a PMC taxonomy for clinical psychologists}

A PMC taxonomy overcomes almost all of the problems clinical psychologists have with DSM. Its only comparative drawback is its relative complexity. But we have seen that, for clinical psychologists, DSM's simplicity has been gained at an unacceptable cost to its validity and clinical utility. Life is complex. People are complex. And DSM has oversimplified them.

Unlike DSM, a PMC taxonomy does not claim that the items it lists are inherently negative. It simply lists discovered cyclic causal sequences. Whether they are viewed as desirable or undesirable is a value judgement. There are as many 'virtuous circles' as there are 'vicious circles'. DSM's controversial conceptual overreach in asserting that, for example, homosexuality or Female Orgasmic Disorder are inherently negative (because they are "mental disorders") is thus avoided.

Psychologists do not simply attempt to alter states or reduce 'symptoms'. They do not merely work to cheer up a sad person or to relax an anxious person. The PMC taxonomy lists problematic ongoing underlying mechanisms or processes that must be addressed. DSM's problems with multifinality and divergent trajectories are also thus overcome.

A PMC taxonomy defines and lists clinical psychological problems as perpetuating cyclic processes. This simple intuitive concept at once confers an essence to CPPs, that is parsimonious (one criterion, not seven or eight), categorical not dimensional, and has intrinsic clinical utility and treatment-relevance.

CPPs, as defined within the PMC model, qualify as essential entities on the eight criteria of such proposed by Haslam and Ernst [8]. The identification of a depression PMC is informative. It tells us much about the person involved. Anxiety PMCs are historically invariant. We know of phobic PMCs from Roman times. Such problems are discrete. There are definable boundaries. They are uniform. People trapped in eating problem PMCs have many similarities. They are, by definition, immutable. They rarely spontaneously remit. There is one necessary feature (a full causal PMC). They are inherent; there is a sameness under the symptoms. And they are natural, and not simply an artificial product of people's efforts to classify made-up mental disorders.

A PMC taxonomy is theory-based, be this PMC theory or evidence-based clinical theory. But, given the cyclic nature of scientific research and theory construction, the 
taxonomy can improve the focus and organisation of research efforts, and the reporting and assemblage of research results.

The proposed PMC coding system can communicate more psychologically-relevant and treatment-relevant information than can DSM's. "Bill Bloggs has been experiencing PMCs 2.3.1 and 2.4.1 for approximately 6 months" is much more psychologically informative - it tells us much more about what has gone wrong and what to do about it - than "Bill Bloggs has been suffering a Major Depressive Disorder for approximately 6 months".

Communicability will be enhanced not only among clinical psychologists. The medical model and PMC theory are compatible and complementary. Already, clinical psychologists accept referrals of diagnosed mental disorders, understand what is meant, do their own functional analyses and case formulations, and often feed these back to the psychiatric or physician referrer, who understands them perfectly well, and may even appreciate a PMC code summary of this formulation.

A taxonomy of PMCs can increase the reliability of case formulation as well as its communicability through standardization of nomenclature. A PMC-based model is also very comprehensible and communicable to clients. Quite complex graphically presented individual case formulations can be simplified, standardized, and described by separating out the individual PMCs involved.

A person who is offered a PMC-based case formulation of their CPP with its explained mechanisms, treatment implications, openings for self-help, and overlap with normality is likely to find this more comprehensible, more optimistic, more empowering, and less stigmatizing than being conferred with a diagnosis of a psychopathology or mental disorder.

Within the model different 'kinds' of psychological problem are recognised and operationally defined (see Table 2). New useful meaning is then conferred on terms such as "counselling", "intervention", "therapy", and "psychopathological".

CPPs that do not conveniently fit the mould of mental disorders, such as relationship problems, or that cross the artificial borders of separate mental disorders, such as 'agitated depression' or alcohol abuse triggered by and perpetuating social anxiety, are fully recognised in a PMC taxonomy. Comorbidity is no longer a theoretical quandary.

\section{But does a PMC taxonomy work better?!}

However, as the primary criterion for any clinical taxonomy is its treatment-relevance [21, 31, 99, 279], the real test of PMC theory is whether it results in more treatment success.

As research around the world has been so completely dominated by the mental disorder model, it is hard to find exceptions in which problem assessment and assessment of improvement are based on a case formulation rather than a diagnosis, let alone comparisons of the two approaches with the same population. Among the few that have been undertaken, the results are clear. This has been true for behavioural therapies based on functional analyses, and then more recently CBT based on case conceptualizations.

With behavioural interventions firstly, Carr and Durand [308] found that the treatment of disruptive behaviour needed to depend on the function it was serving (its maintainer) - whether the behaviour serves an escape function or an attention-seeking function. Durand and Crimmins [309] found that the successful treatment of self-injurious behaviour also depended upon analysis and discrimination as to whether it was maintained by an attention-getting motivation, or was escapemaintained, tangibly-maintained, or sensory-maintained. Schneider and Bryne [310] produced a significantly greater boost in observed social skills and cooperative play among children with various behaviour problems when treatment was individualized rather than standardized. In a post hoc analysis, Eifert et al. [151] discovered that their agoraphobic clients who had by chance found themselves in the treatment condition that happened to target their particular agoraphobic maintenance mechanism (fear of separation, fear of embarrassment,....) did better. Iwata et al. [311] showed that the outcome of treatment of self-injurious behaviour can depend on detection and targeting of the specific factors maintaining the behaviour, not on which diagnosis subsumes it.

Unfortunately, at about the same time that functional analysis or case formulation was being imported to CBT from behavioural analysis [312], the promotion of DSM's diagnostic hegemony was occurring. Despite this, some comparisons of case conceptualization-based treatments - where a case formulation is "a hypothesis about transdiagnostic mechanisms that cause and maintain all of the patient's symptoms and problems" ([313] p.455) - with diagnosis-guided treatment have been undertaken. Interest in such comparisons persisted because "flexible modular treatment is closer to how clinicians actually work than are the EST protocols that target a single disorder with an inflexible series of interventions" ([313] p.456).

For example, Jacobson et al. [314], comparing structured marital therapy with a clinically flexible version, found that couples treated with the strictly structured format had deteriorated significantly more at 6 month followup.

When Litt et al. [315] compared a coping skills-based, individualized assessment and treatment program for alcohol dependence problems with a CBT packaged program, the former resulted in higher rates of abstinence and more reports of in vivo "momentary coping responses". In a similar vein, when the reasons for drug 
use are analysed so that brief coping skills interventions can be matched to personality-specific motives (PMCs) for the substance abuse, treatment efficacy is improved [316].

Persons et al. [317] demonstrated that patients with "multiple comorbidities" especially benefit when empirically supported treatment selection is guided by a case formulation.

In one of the few direct comparison treatment studies, Weisz et al. [318] have found that utilizing a decision flow chart with a modular approach to therapy for children with anxiety, depression, or conduct problems $(\mathrm{MATCH})$ produced significantly quicker improvement than standard treatment, which did not differ significantly from usual care [319].

Also, internet-delivered guided self-help treatment of depression that is individually-tailored has been found more effective with more depressed subjects, and with higher 'comorbidity' subjects than non-tailored standardized treatment or an active (online discussion) control group [320].

Fairburn et al.'s [321] transdiagnostic theory of the maintenance of all eating disorders claims that 'bulimia nervosa', anorexia nervosa, and 'atypical eating disorders' share similar maintaining pathological processes (or PMCs, see Appendix B). So, when they added four more maintaining mechanisms to their model (e.g. concerning mood intolerance, or core low self-esteem) they were proposing four more evidence-based PMCs for the eating problems category of our new taxonomy. It is unsurprising then when Ghaderi [322] found that individualized CBT guided by functional analyses produces better results with 'bulimia nervosa' clients than standardized focused CBT, including in terms of percentage of nonresponders.

So, when case formulations are used to guide treatment rather than clumsy, theory-bereft diagnoses, indications to date are that the subsequent tailored treatments improve our effectiveness. The next step appears to be to improve the reliability, standardization, and validity of case formulation and treatment selection by basing therapeutic trials and outcome studies on PMC-defined rather than DSMdiagnosed experimental groups.

\section{Conclusions and implications}

The Division of Clinical Psychology of the British Psychological Society is one of many bodies that now "believes there is a clear rationale and need for a paradigm shift in relation to functional psychiatric diagnoses" ([17] p.5). However, to date, no universal, radical, cohesive alternative to DSM or ICD for psychologists has arisen.

It is proposed that the next logical step in the scientific development of the discipline of clinical psychology is the formation and dissemination of a taxonomy of CPPs based on its own conceptual scheme and operating primarily at a psychological level. The independent conceptual, research, and clinical development of the profession has advanced sufficiently for this critical step. In fact, it is overdue; seemingly delayed by the hegemony of another profession's corresponding taxonomy - psychiatry's nosology of mental disorders. Benefits to the interactive process of theory development, empirical research, and clinical practice (itself a 'virtuous circle') will ensue.

The proposed taxonomy comprises a listing of psychological-level problem-maintaining circles (PMCs) that distinguish and explain the critical difference between transient, linear, negative psychological (cognitive, emotional, behavioural, situational) events, states, reactions, or experiences (Type I psychological problems), self-perpetuating psychological-level causal loops (CPPs) that warrant, and can be affected by, psychological-level therapeutic intervention (Type II), and problems that can persist even when psychological-level maintainers are nullified (Type III 'psychopathological problems').

The development of the various iterations of the DSM has involved the assignment and coordination of vast numbers of contributors, panels, committees, and task forces. For example, three of the five volumes of the DSM-IV Sourcebook [323] alone commissioned 150 reviews of the literature on psychological disorders. However, these reviews were based on research that was conducted largely within the DSM framework, so much circular reasoning occurred, and alternative approaches or conceptualizations were not considered [31]. Further, DSM's broadly atheoretical approach has made it very difficult, some say impossible, for it to select, interpret, condense, confirm, and incorporate much of the research its panels review. It is a very leaky virtuous circle.

To illustrate the problem at a conceptual level, there is no evidence that the psychopathological condition/mental disorder/mental illness called "Social Anxiety Disorder (Social Phobia)" (DSM300.23) actually exists. There are no reliable or validated biological markers or criteria or measures outside clinical psychological judgement that can detect this 'illness'. It is defined by its effects, which are attributed to its existence [52]. It is an assumption - a convention - constructed for pragmatic, sociological, or political reasons, just as the disease model of alcohol problems and the chemical imbalance theory of depression were. They were developed in an attempt to reduce stigma or encourage people to take their antidepressants. But no evidence supportive of their veracity has emerged since. In fact, some highly deleterious effects on self-esteem, self-efficacy, confidence in treatment, and expectation of recovery have ensued [324]. (Ironically, a diagnosis can thus become a self-fulfilling prophecy, and cause negative feelings, thoughts, or behaviour via vicious circles, such as through instilling shame or hopelessness ([14] p.69).)

On the other hand, bountiful supportive evidence has emerged for the real-world existence and operation of the psychological-level PMC: Excessive, problematic 
social anxiety $\rightarrow$ Overly negative evaluation of one's social performance $\rightarrow$ Unreasonable persistent regrets over social contacts $\rightarrow$ Excessive, problematic social anxiety. There is psychological-level evidence for the existence and operation of every one of these causal links. In fact such evidence led to the development of this model. It is an evidence-based model of a CPP, which in turn directly implies therapy choice. It is treatment-relevant, not by way of indicating which pill, or even which monolithic 12-session therapy package, can 'cure' the 'Excessive, problematic social anxiety', but by suggesting a specific Cognitive Therapy intervention to address the distorted self-evaluation of social performance - to break the $\mathrm{PMC}$ at that point.

The proposed new taxonomy of CPPs is therefore theory-based, treatment-relevant, evidence-informed, and pragmatic. Much research required for its development has already been undertaken. It is now a matter of framing the results (e.g. the evidence-based models of psychopathology) in PMC terms, extracting the smallest simplest units (PMCs) and listing them under generallyuseful clinical categories of presenting problem. This task deserves an effort corresponding to some meaningful fraction of that which has been devoted to DSM's development, promotion, and dissemination.

The independence and standing of the discipline and profession may then be restored, and, more importantly, the millions of people experiencing crippling CPPs may be offered more therapeutically relevant, less stigmatising, more empowering, more evidence-based, and more comprehensible, reliable, and systematic formulations of their problems.

Many uncertainties will remain despite such a clarifying taxonomy. Disagreements will continue as to whether a particular problem is best regarded as a Type I, Type II, or Type III psychological problem. This has long been a conceptual issue (What is a 'mental disorder'?), a research-informed therapeutic issue (e.g. counselling versus CBT versus pharmacotherapy), and a territorial/political issue among the professions. A PMC taxonomy can at least clarify the conceptual issues, and guide research to address the therapeutic issues.

\section{Appendix A}

Many who promote a theory-based taxonomy or classification of clinical psychological problems (CPPs) insist that it must be based on 'etiology' of the problem, as this can best indicate appropriate subsequent treatment (e.g. [31]). This seems to be based on the culturally-entrenched community-wide assumption that to properly 'cure a disease' we must find its 'cause' and reverse or root this out. Anything else is just amelioration or symptomatic treatment, and will not last. The disease will remain, to recur.
But the concept of a 'cause' in this context is often indiscriminately cited to mean two very different entities. It can refer to a precipitant - an historical etiological factor - such as an early loss or recent trauma. Or it can refer to a current explanatory underlying mechanism or process, such as an anxiety response maintained by avoidant behaviour and catastrophic thinking.

Numerous examples can be found in the literature where the ambiguity of the term 'etiology' has caused conceptual, theoretical, and hence clinical confusions (e.g. [14, 31, 325]). Some discussions give onset and maintenance equal weight (e.g. [35]). The transdiagnostic movement has been concerned with both distal risk factors and with proximal within-person processes [105].

But only the latter of these can provide a treatmentrelevant taxonomy. It is not logical or useful to consider any consequence of a traumatic event to be a CPP, while no problem that arises without an identifiable historical cause can be a CPP.

Therefore, the critical 'causes' or 'etiologies' are current maintaining underlying mechanisms. They are what will determine treatment.

This is true even within the medical model. For example, fever and weakness can be 'caused' by an infection (the underlying process). Aspirin will not 'cure' this, but an antibiotic might. We need to know the type of bacteria to determine the treatment. We do not need to know the source of the infection to treat it. This knowledge can be very useful for other reasons - to avoid reinfection, for public health reasons, or to check for susceptibilities in the patient. But for 'cure', the 'cause' we need to know about is the underlying mechanism, the type of bacteria.

The same is even more true in clinical psychology. This has been found empirically. None of the frontline, evidence-supported, best practice, psychological-level therapies listed in outcome meta-analyses require historical cures. Controlled studies do not support the efficacy of rebirthing techniques, hypnotic regression, classical psychoanalysis, traumatic incident reduction, psychodrama, catharsis, or abreaction [134, 326-328].

DSM has been criticized for being atheoretical with regard to the "etiology" of its listed disorders (e.g. [31]). On the other hand, the functional analytic approach of behavioural clinical psychology has been criticized for emphasising current underlying mechanisms rather than historical causes or precipitants. It was accused by psychodynamic theorists of providing only 'symptomatic' or surface explanation and treatment [329]. However, the symptom substitution debates of the 1970s were resolved firmly in favour of the 'symptomatic' treatments [330, 331], perhaps because these treatments were not applied to 'symptoms' at all (a medical model term) but actually to the important current underlying maintaining mechanisms behind CPPs. 
Even when problem onset has been examined, many or most phobias, for example, do not arise from a distinct traumatic conditioning experience [332-335]. It is often unclear where they arise, but it can be clear what is maintaining them. Avoidance is a common maintainer.

Hence, case formulations in CBT, while they may include inputs such as characterological tendencies, historical experiences, attachment issues, and precipitating events, predominantly formulate explanations of the maintenance of a presenting problem [54, 202, 336]. Similarly, transdiagnostic treatment protocols particularly target "common maintaining factors" [117].

\section{Appendix B}

Based on the preceding evidence and arguments, and on the clinical experience of the use of Bakker's [219-221] tentative taxonomy, it is proposed

(a.) That clinical psychological problem codes be prefixed with 'PMC' standing for ProblemMaintaining Circle.

(b.) That three levels of numerical coding be used, in the format "PMC x.y.z". More would be unmanageable. Less would excessively limit the amount of case formulation/functional analytic/ treatment implication information conveyed.

(c.) That the numerical ' $x$ ' codes represent generally recognised, intuitively acceptable presenting problem categories. An example of a start to such a listing is given in Table 3. Included are only those categories addressed in Bakker $[218,220]$.

(d.) 'y' codes represent the major classes of problematic underlying mechanism (PMC element) that have been identified in CBT models of psychopathology and in transdiagnostic research, and that commonly

Table 3 Some proposed ' $x$ ' codes in a 'PMC x.y.z' taxonomy

\begin{tabular}{ll}
\hline $1 . y . z$ & Anxiety \\
$2 . y . z$ & Depression \\
$3 . y . z$ & Relationship Problems \\
$4 . y . z$ & Eating/Weight Problems \\
$5 . y . z$ & Anger Problems \\
$6 . y . z$ & Chronic Pain \\
$7 . y . z$ & OCD \\
$8 . y . z$ & Substance Abuse/Dependence \\
$9 . y . z$ & Sexual Problems \\
$10 . y . z$ & Jealousy Problems \\
$11 . y . z$ & Any Psychological Problem \\
$12 . y . z$ & Type III Psychological Problems \\
$13 . y . z$ & Interactive Clinical Psychological Problems \\
$14 . y . z$ & \\
\hline
\end{tabular}

occur in one or (often) more types of presenting problem. A preliminary listing is provided in Table 4.

As earlier described, the potential list of problemmaintenance mechanisms is enormous. Table 4 only lists some of the most researched, frequently recognised, or treatment-triggering ones. This abundance is the reason that 'underlying mechanism' or 'treatment implication' is not coded at ' $x$ '.

(e.) To describe a problem as being maintained "by avoidance", or "due to reinforcement" is too broad to implicate specific treatment approaches.

Therefore, it is proposed that ' $z$ ' codes represent more specific evidence-based mechanisms under each mechanism type. An example listing is provided in Table 5.

(f.) Type III psychological problems ('psychopathological' problems) are those problems that are not fully explained by psychological-level PMCs, and are rarely fully 'cured' by interventions that disrupt them. However, PMCs are frequently involved, and psychological therapies can often help management, reduce symptomatology, or avoid episodes of relapse. For some such problems, this is currently the best form of therapy available. Table 6 lists some of the conditions currently considered to be Type III (psychopathological) problems.

'z' codes in PMC 12.y.z problems (Table 6) would specify various evidence-based PMCs known to occur in some cases of the disorder, which exacerbate symptomatology, and suggest psychological-level therapies that have been shown to ameliorate, if not resolve, the condition, such as family therapy with schizophrenia or Social Rhythm Therapy [337] for Bipolar Disorder.

(g.) 'PMC 13.y.z' codes represent PMCs which have been found to occur between traditionallydistinguished clinical psychological problems, suggesting that, if detected, treatment targeting PMCs within either or both problems may be indicated.

Table 4 Some proposed ' $y$ ' codes in a 'PMC x.y.z' taxonomy

X.1.z Avoidance (implying exposure therapy)

x.2.z Erroneous Cognitions (implying psychoeducation, cognitive restructuring, thought stopping, self-talk coaching, etc.)

x.3.z Selective Attention/Hypervigilance/Preoccupation (implying attentional control training, thought stopping, etc.)

X.4.z Sleep Disturbance

x.5.z Problematic Reinforcement

x.6.z Narrowed Coping Repertoire 
Table 5 Some proposed ' $z$ ' codes in a 'PMC x.y.z' taxonomy

\begin{tabular}{ll}
\hline$x .1 .1$ & Cognitive avoidance \\
x.1.2 & Emotional avoidance \\
x.1.3 & Behavioural avoidance \\
x.2.1 & Lack of information \\
x.2.2 & 'Irational beliefs' \\
x.2.3 & Negative self-talk/rumination \\
x.3.1 & Seeing threat everywhere \\
x.3.2 & Seeing failure everywhere \\
x.3.3 & Seeing dislike/disrespect everywhere \\
x.4.1 & Low energy levels \\
x.4.2 & Poor concentration/decision making \\
x.4.3 & Effects of nightmares \\
x.4.4 & Mood effects \\
x.5.1 & Attention-seeking reinforcement \\
x.5.2 & Tangible, concrete reinforcement \\
x.5.3 & Escape conditioning \\
x.5.4 & A low reinforcement environment \\
x.6.1 & Resorting to alcohol/drugs \\
x.6.2 & Resorting to escape/denial \\
x.6.3 & Resorting to aggression \\
$x .6 .4$ & Resorting to self-harm \\
$x .6 .5$ & Reduced social support \\
\hline & \\
\hline
\end{tabular}

Table 7 lists examples of these, along with supportive research evidence for their existence. Comorbidity is then not a diagnostic problem. It is a naturally-occurring, informative, and explainable risk, that broadens treatment options.

The interactive problems listed in Table 7 do not represent separately diagnosed mental disorders in the DSM sense. They represent clusters or fields within the symptom matrix of the network model [27]. Hence the labels are chosen for their clinical utility only. For

Table 6 Some proposed 'PMC 12.y.z' codes in a 'PMC x.y.z' taxonomy

\begin{tabular}{ll}
\hline $12.1 . z$ & Schizophrenia \\
$12.2 . z$ & Bipolar Disorder \\
$12.3 . z$ & Autism \\
$12.4 . z$ & ADHD \\
$12.5 . z$ & Delusion Disorder \\
$12.6 . z$ & Chronic Fatigue Syndrome \\
$12.7 . z$ & Premenstrual Dysphoric Disorder \\
$12.8 . z$ & \\
\hline
\end{tabular}

Table 7 Some proposed 'PMC 13.y.z' codes in a 'PMC x.y.z' taxonomy

\begin{tabular}{ll}
\hline $13.1 . z$ & Anxiety \& Depression [239, 338-340] \\
$13.2 . z$ & Anxiety \& Substance Abuse [239, 241, 341] \\
$13.3 . z$ & Depression \& Substance Abuse [239] \\
$13.4 . z$ & Chronic pain \& Anxiety [242] \\
$13.5 . z$ & Chronic pain \& Depression [342, 343] \\
$13.6 . z$ & Depression \& Sexual Dysfunction [240] \\
$13.7 . z$ & \\
\hline
\end{tabular}

example, 'Anxiety' includes PTSD, Social Phobia, etc. And 'Sleep Disorder' could be elevated to the status of a separate comorbid presenting problem, or remain a part of the network field incorporated in 'Depression,'Anxiety', etc.

Much is omitted, and probably critically misrepresented, in Tables 3, 4, 5, 6 and 7. Correction of these errors is exactly what will indicate consensus evidencebased advancement of the scientific framework of clinical psychology.

\section{Abbreviations}

ADHD: Attention Deficit Hyperactivity Disorder; APA: American Psychological Association; APS: Australian Psychological Society; ASD: Acute Stress Disorder; BPS: British Psychological Society; CBT: Cognitive Behaviour Therapy; CISD: Critical Incident Stress Debriefing; CPP: Clinical Psychological Problem; $C T$ : Cognitive therapy; DCP: Division of Clinical Psychology of the British Psychological Society; DSM: Diagnostic and Statistical Manual of the American Psychiatric Association; EST: Evidence Supported Therapy; ET: Exposure Therapy; GAD: Generalized Anxiety Disorder; ICD: International Classification of Diseases and Related Health Problems; MDD: Major Depressive Disorder; PMC: Problem-Maintaining Circle; PTSD: Posttraumatic Stress disorder; RDoC: Research Domain Criteria; UK: United Kingdom; WHO: World Health Organisation

\section{Acknowledgements}

Not applicable.

Authors' contributions

GB is sole author. The author read and approved the final manuscript.

Funding

Not applicable.

Availability of data and materials Not applicable.

Ethics approval and consent to participate

Not applicable.

\section{Consent for publication}

Not applicable.

\section{Competing interests}

The author declares that he has no competing interests.

Received: 14 March 2018 Accepted: 12 June 2019

Published online: 10 July 2019

References

1. Ellis B. Essentialism and natural kinds. In: Psillos S, Curd M, editors. The Routledge companion to philosophy of science. London: Routledge; 2010. p. $139-48$.

2. Glennan S. Mechanisms. In: Psillos S, Curd M, editors. The Routledge companion to philosophy of science. London: Routledge; 2010. p. 376-84 
3. Kuhn TS. The structure of scientific revolutions. 3rd ed. Chicago: University of Chicago Press; 1996.

4. Mansell W, Harvey A, Watkins E, Shafran R. Conceptual foundations of the transdiagnostic approach to CBT. J Cogn Psychother. 2009;23:6-19.

5. Neale JM, Liebert RM. Science and behavior: an introduction to methods and research. 3rd ed. New Jersey: Prentice-Hall; 1986.

6. Thase ME. Major depressive disorder. In: Andrasik F, editor. Comprehensive handbook of personality and psychopatheology: Vol. 2: Adult psychopathology. Hoboken, NJ: Wiley; 2006. p. 207-30.

7. Lawrence RE, Rasinski KA, Yoon JD, Curlin FA. Physicians' beliefs about the nature of addiction: a survey of primary care physicians and psychiatrists. Am J Addict. 2013;22:255-60.

8. Haslam N, Ernst D. Essentialist beliefs about mental disorders. J Soc Clin Psychol. 2002;21:628-44.

9. American Psychiatric Association. Diagnostic and statistical manual of mental disorders. 3rd ed. Washington DC: American Psychiatric Association; 1980.

10. American Psychiatric Association. Diagnostic and statistical manual of mental disorders. 5th ed. Arlington: American Psychiatric Association; 2013.

11. American Psychological Association. APA's statement on the DSM-5 development process, vol. 43. Washington DC; 2012. p. 1. Retrieved from: http://www.apa.org/monitor/2012/01/statement-dsm.

12. Deacon BJ. The biomedical model of mental disorder: a critical analysis of its validity, utility, and effects on psychotherapy research. Clin Psychol Rev. 2013;33:846-61.

13. Frances A. Saving normal: an insider's revolt against out-of-control psychiatric diagnosis, DSM-5, big pharma, and the medicalization of ordinary life. New York: William Morrow \& Co; 2013.

14. Johnstone L. A straight talking introduction to psychiatric diagnosis. Rosson-Wye: PCCS Books; 2014.

15. Lilienfeld SO. DSM-5: centripetal and centrifugal antiscientific forces. Clin Psychol Sci Pract. 2014;21:269-79.

16. Timimi S. No more psychiatric labels: why formal psychiatric diagnostic systems should be abolished. Int I Clin Health Psychol. 2014;14:208-15.

17. DCP. Position statement on the classification of behavior and experience in relation to functional psychiatric diagnoses: Time for a paradigm shift. Leicester: British Psychological Society; 2013.

18. Kendler KS. An historical framework for psychiatric nosology. Psychol Med. 2009:39:1935-41.

19. American Psychiatric Association. Diagnostic and statistical manual of mental disorders. 3rd ed. revised ed. Washington DC: American Psychiatric Association; 1987.

20. Gresham FM, Gansle KA. Misguided assumptions of DSM-III-R: implications for school psychological practice. Sch Psychol Q. 1992;7:79-95.

21. Hyman SE. The diagnosis of mental disorders: the problem of reification. Annu Rev Clin Psychol. 2010;6:155-79.

22. Decker HS. The making of DSM-III: a diagnostic manual's conquest of American psychiatry. New York: Oxford University Press; 2013.

23. Bracken $\mathrm{P}$, Thomas $\mathrm{P}$, Timimi $\mathrm{S}$, et al. Psychiatry beyond the current paradigm. Br J Psychiatry. 2012;201:430-4.

24. Hyman SE. Can neuroscience be integrated into DSM-V? Nat Rev Neurosci. 2007:8:725-32.

25. Kingdon D, Young AH. Research into putative biological mechanisms of mental disorders has been of no value to clinical psychiatry. Br J Psychiatry. 2007;191:285-90.

26. Kupfer DJ. Chair of DSM-5 task force discusses future of mental health research. News release: American Psychiatric Association; 2013.Available at http://www.psychiatry.org/advocacy--newsroom/news-releases/13-33statement-from-dsm-chair-david-kupfer--md.pdf.

27. Cramer AOJ, Waldorp LJ, van der Maas HLJ, Borsboom D. Comorbidity: a network perspective. Behav Brain Sci. 2010;33:137-93.

28. Kessler RC, Chiu WT, Demler O, Walters E. Prevalence, severity, and comorbidity of 12-month DSM-IV disorders in the National Comorbidity Survey Replication. Arch Gen Psychiatry. 2005;62:617-27.

29. Ormel J, Raven D, van Oort F, et al. Mental health in Dutch adolescents: a TRAILS report on prevalence, severity, age of onset, continuity and comorbidity of DSM disorders. Psychol Med. 2015;45:345-60.

30. Teesson M, Slade T, Mills K. Comorbidity in Australia: findings of the 2007 National Survey of mental health and wellbeing. Aust N Z J Psychiatry. 2009; 43:606-14.

31. Clark LA, Watson D, Reynolds S. Diagnosis and classification of psychopathology: challenges to the current system and future directions. Annu Rev Psychol. 1995;46:121-53.
32. Kim NS, Ahn W. Clinical psychologists' theory-based representations of mental disorders predict their diagnostic reasoning and memory. J Exp Psychol Gen. 2002;131:451-76.

33. Zimmerman M, Ellison W, Young D, Chelminski I, Dalrymple K. How many different ways do patients meet the diagnostic criteria for major depressive disorder? Compr Psychiatry. 2015;56:29-34.

34. Andersson G, Ghaderi A. Overview and analysis of the behaviorist criticism of the diagnostic and statistical manual of mental disorders (DSM). Clin Psychol. 2006;10:67-77.

35. Hayes SC, Wilson KG, Gifford EV, Follette VM, Strosahl K. Experiential avoidance and behavioral disorders: a functional dimensional approach to diagnosis and treatment. J Consult Clin Psychol. 1996:64:1152-68.

36. Kupfer DJ, First MB, Regier DA, editors. A research agenda for DSV-5. Arlington: American Psychiatric Association; 2002.

37. Sussman N. Why replication matters. Prim Psychiatry. 2009;16:14-5.

38. Kapur S, Phillips AG, Insel TR. Why has it taken so long for biological psychiatry to develop clinical tests and what to do about it? Mol Psychiatry. 2012;17:1174-9.

39. Kendler KS. Levels of explanation in psychiatric and substance use disorders: implications for the development of an etiologically based nosology. Mol Psychiatry. 2012;17:11-21.

40. Kendler KS, Zachar P, Craver C. What kinds of things are psychiatric disorders? Psychol Med. 2011;41:1143-50.

41. Bostic JQ, Rho Y. Target-symptom psychopharmacology: between the forest and the trees. Child Adolesc Psychiatr Clin N Am. 2006;15:289-302.

42. Mohamed S, Rosenheck RA. Pharmacotherapy of PTSD in the U.S. Department of Veterans Affairs: diagnostic- and symptom-guided drug selection. J Clin Psychiatry. 2008;69:959-65.

43. Taylor D. Prescribing according to diagnosis: how psychiatry is different World Psychiatry. 2016;15:224-5.

44. First MB, Rebello TJ, Keeley JW, et al. Do mental health professionals use diagnostic classifications the way we think they do? A global survey. World Psychiatry. 2018;17:187-95.

45. Insel T, Cuthbert B, Garvey M, Heinssen R, et al. Research domain criteria (RDoC): toward a new classification framework for research on mental disorders. Am J Psychiatr. 2010;167:748-51.

46. Sharfstein S. Big pharma and American psychiatry: the good, the bad and the ugly. Psychiatr News. 2005;40:3.

47. Clark LA, Cuthbert B, Lewis-Fernandez R, et al. Three approaches to understanding and classifying mental disorder: ICD-11, DSM-5, and the National Institute of Mental Health's research domain criteria (RDoC). Psychol Sci Public Interest. 2017;18:72-145.

48. Reed GM. HiTOP must meet the use requirements of the ICD before it can aspire to replace it. World Psychiatry. 2018;17:296-8.

49. Kotov R, Krueger RF, Watson D. A paradigm shift in psychiatric classification: the hierarchical taxonomy of psychopathology (HiTOP). World Psychiatry. 2018;17:24-5.

50. Casey BJ, Craddock N, Cuthbert BN, et al. DSM-5 and RDoC: Progress in psychiatry research? Nat Rev Neurosci. 2013;14:810-4.

51. Bieling PJ, Kuyken W. Is cognitive case formulation science or science fiction. Clin Psychol Sci Pract. 2003;10:52-69.

52. Carey TA, Pilgrim D. Diagnosis and formulation: what should we tell the students? Clin Psychol Psychother. 2010;17:447-54.

53. Hofmann SG. Toward a cognitive-behavioral classification system for mental disorders. Behav Ther. 2014;45:576-87.

54. Persons JB. The case formulation approach to cognitive-behavior therapy. New York: Guilford Press; 2008.

55. Rose PR. Human agency in the neurocentric age. EMBO Reports. 2006;6: 1001-1005.

56. Satel S, Lilienfeld SO. Brainwashed: the seductive appeal of mindless neuroscience. New York: Basic Books; 2013.

57. Gold I. Reduction in psychiatry. Can J Psychiatr. 2009:54:506-12.

58. Dennett DC. Darwin's dangerous idea: evolution and the meanings of life. New York: Touchstone; 1995

59. McHugh PR, Slaveney PR. The perspectives of psychiatry. 2nd ed. Baltimore: Johns Hopkins University Press; 1998.

60. Haslam N. Kinds of kinds: a conceptual taxonomy of psychiatric categories. Philos Psychiatry Psychol. 2002;9:203-17.

61. Zachar P, Kendler KS. Psychiatric disorders: a conceptual taxonomy. Am J Psychiatr. 2007;164:557-65. 
62. Haslam N. Symptom networks and psychiatric categories. Behav Brain Sci. 2010;33:158-9.

63. Keel PK, Klump KL. Are eating disorders culture-bound syndromes? Implications for conceptualizing their etiology. Psychol Bull. 2003;129:747-69.

64. Brown TA, Barlow DH. A proposal for a dimensional classification system based on the shared features of the DSM-IV anxiety and mood disorders: implications for assessment and treatment. Psychol Assess. 2009;21:256-71.

65. Carr A, McNulty M. Classification and epidemiology. In: Carr A, McNulty M, editors. The handbook of clinical psychology: an evidence-based practice approach. London: Routledge; 2006. p. 42-60.

66. Follette WC, Houts AC. Models of scientific progress and the role of theory in taxonomy development: a case study of the DSM. J Consult Clin Psychol. 1996;64:1120-32.

67. Cuthbert BN, Insel TR. Toward the future of psychiatric diagnosis: the seven pillars of RDoC. BMC Med. 2013;11:126-34

68. Chmielewski M, Clark LA, Bagby RM, Watson D. Method matters: understanding diagnostic reliability in DSM-IV and DSM-5. J Abnorm Psychol. 2015;124:764-9.

69. Kotov R, Krueger RF, Watson D, et al. The hierarchical taxonomy of psychopathology (HiTOP): a dimensional alternative to traditional nosologies. J Abnorm Psychol. 2017:126:454-77.

70. Markon KE, Chmielewski M, Miller CJ. The reliability and validity of discrete and continuous measures of psychopathology: a quantitative review. Psychol Bull. 2011;137:856-79.

71. Haslam N, Holland E, Kuppens P. Categories versus dimensions in personality and psychopathology: a quantitative review of taxometric research. Psychol Med. 2012;42:903-20.

72. Wright AG, Krueger RF, Hobbs MJ, Markon KE, Eaton NR, Slade T. The structure of psychopathology: toward an expanded quantitative empirical model. J Abnorm Psychol. 2013;122:281-94.

73. Meehl PE. What's in a taxon? J Abnorm Psychol. 2004;113:39-50.

74. Murray G. Five things you need to know about DSM. InPsych. 2013;35:30-1.

75. Wakefield JC. The concept of mental disorder: on the boundary between biological facts and social values. Am Psychol. 1992;47(3):373-88.

76. Kirk SA, Kutchins H. Making us crazy: DSM - the psychiatric bible and the creation of mental disorder. New York/London: The Free Press; 1997.

77. Zachar P. Psychiatric disorders are not natural kinds. Philos Psychiatry Psychol. 2000;7:167-82

78. Zachar P. Real kinds but no true taxonomy. In: Kendler R, Pamas J, editors. Philosophical issues in psychiatry. Baltimore: John Hopkins University Press; 2008.

79. Borsboom D, Epskamp S, Kievit RA, Cramer AO, Schmittmann VD. Transdiagnostic networks: commentary on Nolen-Hoeksema and Watkins (2011). Perspect Psychol Sci. 2011;6:610-4

80. Kiesler DJ. Beyond the disease model of mental disorders. Westport: Praeger; 1999

81. Zachar P, Kendler KS. Philosophical issues in the classification of psychopathology. In: Zachar P, Kendler KS, editors. Contemporary directions in psychopathology: scientific foundations of the DSM-IV and ICD-II. New York: The Guilford Press; 2010. p. 127-48.

82. Bracken PJ. Postmodernism and psychiatry. Current Opinion In Psychiatry. 2003;16:673-677.

83. Ingleby D. Critical psychiatry: the politics of mental health. New York: Pantheon; 1980.

84. Kendell $\mathrm{R}$, Jablensky A. Distinguishing between the validity and utility of psychiatric diagnoses. Am J Psychiatr. 2003;160:4-12.

85. Varga S. Defining mental disorder. Exploring the 'natural function' approach. Philos Ethics Humanit Med. 2011;6:1.

86. Kraemer HC, Noda A, O'Hara R. Categorical versus dimensional approaches to diagnosis: methodological challenges. J Psychiatr Res. 2004;38:17-25.

87. Lezenweger MF, Depue RA. Toward a developmental psychopathology of personality disturbance: a neurobehavioral dimensional model incorporating genetic, environmental, and epigenetic factors. In: Cicchetti D, editor. Developmental psychopathology: Maladaptation and psychopathology. Vol. 3. 3rd ed. Hoboken: Wiley; 2016. p. 1079-109.

88. Bach B, First MB. Application of the ICD-11 classification of personality disorders. BMC Psychiatry. 2018;18:351. https://doi.org/10.1186/s12888-018-1908-3.

89. Reed GM, Sharan P, Rebello TJ, et al. The ICD-11 developmental field study of reliability of diagnoses of high-burden mental disorders: results among adult patients in mental health settings in 13 countries. World Psychiatry. 2018;17:174-86.
90. Reed GM, Keeley JW, Rebello TJ, et al. Clinical utility of ICD-11 diagnostic guidelines for high-burden mental disorders: results from mental health settings in 13 countries. World Psychiatry. 2018;17:306-15.

91. Stein DJ, Reed GM. ICD-11: the importance of a science of psychiatric nosology. Lancet Psychiatry. 2019;6:6-7.

92. Knapp AA, Blumenthal $H$, Mischel ER, et al. Anxiety sensitivity and its factors in relation to generalized anxiety disorder among adolescents. J Abnorm Child Psychol. 2016;44:233-44.

93. Kupfer DJ, Thase ME. Laboratory studies and validity of psychiatric diagnosis: has there been progress? In: Barret JE, editor. The validity of psychiatric diagnosis. New York: Raven; 1989. p. 177-201.

94. Melville CA, Johnson PCD, Smiley E, et al. Problem behaviours and symptom dimensions of psychiatric disorders in adults with intellectual disabilities: an exploratory and confirmatory factor analysis. Res Dev Disabil. 2016:55:1-13.

95. Shackman AJ, Tromp DPM, Stockbridge MD, et al. Dispositional negativity: an integrative psychological and neurobiological perspective. Psychol Bull. 2016;142:1275-314.

96. Carragher $\mathrm{N}$, Teesson M, Sunderland $\mathrm{M}$, et al. The structure of adolescent psychopathology: a symptom-level analysis. Psychol Med. 2016;46:981-94.

97. Tucker GJ. Putting DSM-IV in perspective. Am J Psychiatr. 1998;155:159-61.

98. DCP. Good practice guidelines on the use of psychological formulation. Leicester: British Psychological Society; 2011.

99. Bissett RT, Hayes SC. The likely success of functional analysis tied to the DSM. Behav Res Ther. 1999;37:379-83.

100. Callahan SA, Panichelli-Mindel SM, Kendall PC. DSM-IV and internalizing disorders: modifications, limitations, and utility. Sch Psychol Rev. 1996;25: 297-307.

101. Follette WC. Introduction to the special section on the development of theoretically coherent alternatives to the DSM system. J Consult Clin Psychol. 1996;64:1117-9.

102. Hayes SC, Nelson RO, Jarrett R. Treatment utility of assessment: a functional approach to evaluating the quality of assessment. Am Psychol. 1987;42:963-74.

103. Kratochwill TR, McGivern JE. Clinical diagnosis, behavioral assessment, and functional analysis: examining the connection between assessment and intervention. Sch Psychol Rev. 1996:25:342-55.

104. McHugh PR, Slavney PR. Mental illness: comprehensive evaluation or checklist? N Engl J Med. 2012:366:1853-5.

105. Nolen-Hoeksema S, Watkins ER. A heuristic for developing transdiagnostic models of psychopathology: explaining multifinality and divergent trajectories. Perspect Psychol Sci. 2011;6:589-609.

106. Cicchetti D, Rogosch FA. Equifinality and multifinality in developmental psychopathology. Dev Psychopathol. 1996;8:597-600.

107. Monroe SM. Modern approaches to conceptualizing and measuring human life stress. Annu Rev Clin Psychol. 2008:4:33-52.

108. Brown TA, Di Nardo PA, Lehman CL, Campbell LA. Reliability of DSM-IV anxiety and mood disorders: implications for the classification of emotional disorders. J Abnorm Psychol. 2001;110:49-58.

109. Barlow DH, Allen LB, Choate ML. Toward a unified treatment for emotional disorders. Behav Ther. 2004;35:205-30.

110. Harvey AG, Watkins ER, Mansell W, Shafran R. Cognitive behavioral processes across psychological disorders: a transdiagnostic approach to research and treatment. Oxford: Oxford University Press; 2004.

111. Kring AM, Sloan DM. Emotion regulation and psychopathology: a transdiagnostic approach to etiology and treatment. New York: Guilford Press; 2010.

112. Krueger RF. The structure of common mental disorders. Arch Gen Psychiatry. 1999;56:921-6.

113. Rozin P, Royzman EB. Negativity bias, negativity dominance, and contagion. Personal Soc Psychol Rev. 2001;5:296-320.

114. Boulanger JL, Hayes SC, Pistorello J. Experiential avoidance as a functional contextual concept. In: Kring AM, Sloan DM, editors. Emotion regulation and psychopathology: a transdiagnostic approach to etiology and treatment. New York: Guilford Press; 2010. p. 107-36.

115. Nolen-Hoeksema S, Wisco BE, Lyubomirsky S. Rethinking rumination. Perspect Psychol Sci. 2008;3:400-24.

116. Hayes SC, Strosahl KD, Wilson KG, Bissett RT, et al. Measuring experiential avoidance: a preliminary test of a working model. Psychol Rec. 2004:54:553-78.

117. McEvoy PM, Nathan P, Norton PJ. Efficacy of transdiagnostic treatments: a review of published outcome studies and future research directions. J Cogn Psychother. 2009;23:20-33. 
118. Weitz E, Kleiboer A, van Straten A, Cuijpers P. The effects of psychotherapy for depression on anxiety symptoms: a meta-analysis. Psychol Med. 2018;48: 2140-52.

119. Thompson-Hollands J, Sauer-Zavala S, Barlow DH. CBT and the future of personalized treatment: a proposal. Depress Anxiety. 2014;31:909-11.

120. Hopwood C, Bagby RM, Gralnick TM, et al. Integrating psychotherapy with the hierarchical taxonomy of psychopathology (HiTOP). J Psychother Integr. https://doi.org/10.31234/osf.io/jb8z4 (in press).

121. Forbush KT, Watson D. The structure of common and uncommon mental disorders. Psychol Med. 2013;43:97-108.

122. Kotov R, Ruggero CJ, Krueger RF, Watson D, Yuan Q, Zimmerman M. New dimensions in the quantitative classification of mental illness. Arch Gen Psychiatry. 2011;68:1003-11.

123. Slade T, Watson D. The structure of common DSM-IV and ICD-10 mental disorders in the Australian general population. Psychol Med. 2006;36:1593-600.

124. Eaton NR, Rodriguez-Seijas C, Carragher N, Krueger RF. Transdiagnostic factors of psychopathology and substance use disorders: a review. Soc Psychiatry Psychiatr Epidemiol. 2015;50:171-82.

125. Emmelkamp PMG, David D, Beckers T, et al. Advancing psychotherapy and evidence-based psychological interventions. Int J Methods Psychiatr Res. 2014;23(Suppl.1):58-91.

126. Regier DA, Narrow WE, Kuhl EA, Kupfer DJ. The conceptual development of DSM-V. Am J Psychiatr. 2009;166:645-50.

127. Reiss D, Emde RN. Relationship disorders are psychiatric disorders: five reasons they were not included in the DSM-IV. In: Phillips KA, First MB, Pincus HA, editors. Advancing DSM: dilemmas in psychiatric diagnosis. Washington DC: American Psychiatric Press; 2003. p. 191-223.

128. Sperry L, Duffy MP, Tureen RM, Gillig SE. Psychopathology. In: Sperry L, Duffy MP, Tureen RM, Gillig SE, editors. Family therapy review: preparing for comprehensive and licensing examinations. Mahwah: Lawrence Erlbaum; 2005. p. 67-85.

129. Patterson GR. Coercive family process. Eugene: Castalia; 1982.

130. Dishion TJ, Patterson GR, Kavanagh KA. An experimental test of the coercion model: linking theory, measurement, and intervention. In: McCord J, Tremblay RE, editors. Preventing antisocial behavior. New York: Guilford; 1992. p. 253-82.

131. Messer S, Slife BD, Williams RN, Barlow D, editors. Critical issues in psychotherapy: translating new ideas into practice. Thousand Oaks: Sage; 2001.

132. Howard Kl, Moras K, Brill PL, Martinovich Z, Lutz W. Evaluation of psychotherapy: efficacy, effectiveness, and patient progress. Am Psychol. 1996;51:1059-64

133. Westen D, Novotny C, Thompson-Brenner $\mathrm{H}$. The empirical status of empirically supported therapies: assumptions, methods, and findings. Psychol Bull. 2004;130:631-63.

134. Roth A, Fonagy P, editors. What works for whom? A critical review of psychotherapy research. 2nd ed. New York: Guilford Press; 2005.

135. Dobson D, Dobson KS. Evidence-based practice of cognitive-behavioral therapy. New York: Guilford Press; 2009.

136. Davis LJ. Obsession: a history. Chicago: University of Chicago Press; 2008.

137. King DB, Niess AB, Maddi AE, Perkins LS. The rise of abnormal psychology during the progressive era: reflections from an American scientific periodical. In: Plante TG, editor. Abnormal psychology across the ages. Santa Barbara: Praeger; 2013. p. 73-86.

138. Tracy SW. Medicalizing alcoholism one hundred years ago. Harv Rev Psychiatry. 2007;15:86-91.

139. Haynes SN. The assessment-treatment relationship and functional analysis in behavior therapy. Eur J Psychol Assess. 1998;14:26-35.

140. Schomerus G, Schwahn C, Holzinger A, et al. Evolution of public attitudes about mental illness: a systematic review and meta-analysis. Acta Psychiatr Scand. 2012;125:440-52.

141. Hinshaw SP. The mark of shame: stigma of mental illness and an agenda for change. New York: Oxford University Press; 2007

142. Pitt L, Kilbride M, Welford M, Nothard S, Morrison AP. Impact of a diagnosis of psychosis: user-led qualitative study. Psychiatr Bull. 2009;33:419-23.

143. Kroska A, Harkness SK. Exploring the role of diagnosis in the modified labelling theory of mental health. Soc Psychol Q. 2008;71:193-208.

144. Magliano L, Read J, Rega S, Oliviero N, et al. The influence of causal explanations and diagnostic labelling on medical students' views of schizophrenia. Acad Med. 2011;86:1155-62.

145. Read J, Haslam N, Sayce L, Davies E. Prejudice and schizophrenia: a review of the 'mental illness is an illness like any other' approach. Acta Psychiatr Scand. 2006;114:303-18.
146. Angermeyer MC, Holzinger A, Carta MG, Schomerus G. Biogenetic explanations and public acceptance of mental illness: systematic review of population studies. Br J Psychiatry. 2011;199:367-72.

147. Seeman N, Tang S, Brown AD, Ing A. World survey of mental illness stigma. J Affect Disord. 2016;190:115-21.

148. Kvaale EP, Gottdiener WH, Haslam N. Biogenetic explanations and stigma: a meta-analytic review of associations among laypeople. Soc Sci Med. 2013; 96:95-103.

149. Haslam N, Kvaale EP. Biogenetic explanations of mental disorder: the mixed blessings model. Curr Dir Psychol Sci. 2015;24:399-404.

150. Brooke S. Formulation in clinical psychology: past, present and future. Clin Psychol. 2004;41:36-9.

151. Eifert GH, Evans IM, McKendrick VG. Matching treatments to client problems not diagnostic labels: a case for paradigmatic behavior therapy. J Behav Ther Exp Psychiatry. 1990;21:163-72.

152. Cuipers P, van Straten A, Andersson G, van Oppen P. Psychotherapy for depression in adults: a meta-analysis of comparative outcome studies. J Consult Clin Psychol. 2008;76:909-22.

153. Dobson KS, Hollon SD, Dimidjian S, et al. Randomized trial of behavioral activation, cognitive therapy, and antidepressant medication in the prevention of relapse and recurrence in major depression. J Consult Clin Psychol. 2008;76:468-77.

154. Ougrin D. Efficacy of exposure versus cognitive therapy in anxiety disorders: systematic review and meta-analysis. BMC Psychiatry. 2011;11:200. https:// doi.org/10.1186/1471-244X-11-200.

155. Powers MB, Sigmarsson SR, Emmelkamp PMG. A meta-analytic review of psychological treatments for social anxiety disorder. Int J Cogn Ther. 2008;1: 94-113.

156. Michelson L, Mavissakavalian M, Marchione K. Cognitive, behavioral, and psychophysiological treatment of agoraphobia: a comparative outcome investigation. Behav Ther. 1988;19:97-120.

157. Wolpe J. How indifference to individual differences has made a mockery of outcome research. Paper presented at the 23rd annual convention of the Association for Advancement of Behavior Therapy. Washington DC; 1989.

158. Wolpe J. The derailment of behavior therapy: a tale of conceptual misdirection. J Behav Ther Exp Psychiatry. 1989;20:3-15.

159. Smith GT, McCarthy DM, Zapolski TCB. On the value of homogeneous constructs for construct validation, theory testing, and the description of psychopathology. Psychol Assess. 2009;21:272-84.

160. Deaton A, Cartwright N. Understanding and misunderstanding randomized controlled trials. Soc Sci Med. 2018;210:2-21.

161. Barlow DH, Allen L, Choate ML. Toward a unified treatment for emotional disorders - republished article. Behav Ther. 2016:47:838-53.

162. Rapee RM, Gaston JE, Abbott MJ. Testing the efficacy of theoretically derived improvements in the treatment of social phobia. J Consult Clin Psychol. 2009;77:317-27.

163. Parkes CM. Grief as a psychological transition process of adaptation to change. In: Stroebe M, Stroebe W, Hanson RO, editors. Handbook of bereavement: theory, research and intervention. New York: Cambridge University Press; 1993.

164. Windholz MJ, Marmar CR, Horowitz M. A review of the research on conjugal bereavement: impact on health and efficacy of intervention. Compr Psychiatry. 1985;26:433-47.

165. Bryant RA. Early predictors of posttraumatic stress disorder. Biol Psychiatry. 2003:53:789-98

166. Tennant C, Bebbington P, Hurry J. The short-term outcome of neurotic disorders in the community: the relation of remission to clinical factors and to "neutralizing" life events. Br J Psychiatry. 1981;139:213-20.

167. Bonanno GA, Wortman CB, Lehman DR, et al. Resilience to loss and chronic grief: a prospective study from pre-loss to 18 months post-loss. J Pers Soc Psychol. 2002;83:1150-64.

168. Greer S. Bereavement care: some clinical observations. Psycho-Oncology. 2010;19:1156-60.

169. Giese J, Mathews R. Revisions in the DSM-5: What's changed? InPsych. 2013; $35: 28-9$.

170. Stroebe MS, Schut H. The dual process model of coping with bereavement: rationale and description. Death Stud. 1999:23:197-224.

171. Worden JW. Grief counseling and grief therapy: a handbook for the mental health practitioner. 4th ed. New York: Springer; 2008.

172. Cooper R. Complicated grief, philosophical perspectives. In: Stroebe M, Schut $H$, van den Bout J, editors. Complicated grief: scientific foundations for health care professionals. New York: Routledge/Taylor \& Francis Group; 2013. p. 13-26. 
173. Boelen PA, Hout M, van den Bout J. Prolonged grief disorder: cognitivebehavioral theory and therapy. In: Stroebe M, Schut H, van den Bout editors. Complicated grief: scientific foundations for health care professionals. New York: Routledge/Taylor \& Francis Group; 2013. p. 221-34.

174. Schut H, Stroebe MS. Interventions to enhance adaptation to bereavement. J Palliat Med. 2005:8:140-7.

175. Creamer M, Burgess P, McFarlane AC. Posttraumatic stress disorder: findings from the Australian National Survey of mental health and well-being. Psychol Med. 2001;31:1237-47.

176. Kessler RC, Sonnega A, Bromet E, Hughes M. Posttraumatic stress disorder in the National Comorbidity Survey. Arch Gen Psychiatry. 1995;52:1048-60.

177. Litz BT, editor. Early intervention for trauma and traumatic loss. New York: Guilford Publications; 2004

178. North CS, Smith EM, McCool RE, Lightcap PE. Acute postdisaster coping and adjustment. J Trauma Stress. 1989;2:353-60.

179. Riggs DS, Rothbaum BO, Foa EB. A prospective examination of symptoms of posttraumatic stress disorder in victims of non-sexual assault. J Interpers Violence. 1995:2:201-14.

180. Zayfert C, Becker CB. Cognitive-behavioral therapy for PTSD. New York: The Guilford Press; 2007.

181. Devilly GJ, Cotton P. Psychological debriefing and the workplace: defining a concept, controversies and guidelines for intervention. Aust Psychol. 2003; 38:144-50.

182. Bryant RA, Harvey AG, editors. Acute stress disorder: a handbook of theory, assessment, and treatment. Washington DC: American Psychological Association; 2000.

183. Zlotnick C, Warshaw M, Shea MT, Keller MB. Trauma and chronic depression among patients with anxiety disorders. J Consult Clin Psychol. 1997;65:333-6.

184. Keane TM, Barlow DH. Posttraumatic stress disorder. In: Barlow DH, editor. Anxiety and its disorders: the nature and treatment of anxiety and panic. 2nd ed. New York: Guilford Press; 2002. p. 418-53.

185. Bryant RA, Harvey AG. Avoidant coping style and post-traumatic stress following motor vehicle accidents. Behav Res Ther. 1995;33:631-5.

186. Carr VJ, Lewin TJ, Kenardy JA, Webster RA, et al. Psychosocial sequelae of the 1989 Newcastle earthquake: III. Role of vulnerability factors in postdisaster morbidity. Psychol Med. 1997;27:179-90.

187. Kenardy J, Tan L. The role of avoidance coping in the disclosure of trauma. Behav Chang. 2006:23:42-54.

188. Marx BP, Sloan DM. Peritraumatic dissociation and experiential avoidance as predictors of posttraumatic stress symptomatology. Behav Res Ther. 2005;43: 569-83

189. Plumb JC, Orsillo SM, Luterek JA. A preliminary test of the role of experiential avoidance in post-event functioning. J Behav Ther Exp Psychiatry. 2004;35:245-59.

190. Bryant RA, Moulds ML, Guthrie RM, et al. A randomized controlled trial of exposure therapy and cognitive restructuring for posttraumatic stress disorder. J Consult Clin Psychol. 2008;76:695-703.

191. Wirtz PW, Harrell AV. Effects on postassault exposure to attack-similar stimuli on long-term recovery of victims. J Consult Clin Psychol. 1987;55:10-6.

192. Morina N, Stangier U, Risch AK. Experiential avoidance in civilian war survivors with current versus recovered posttraumatic stress disorder: a pilot study. Behav Chang. 2008;25:15-22.

193. Devilly GJ, Gist R, Cotton P. Ready! Fire! Aim! The status of psychological debriefing and therapeutic interventions: in the workplace and after disasters. Rev Gen Psychol. 2006;10:318-45.

194. Mayou RA, Ehlers A, Hobbs M. Psychological debriefing for road traffic accident victims: three-year followup of a randomized controlled trial. $\mathrm{Br} J$ Psychiatry. 2000;176:589-93.

195. van Emmerik AAP, Kamphuis JH, Hulsbosch AM, Emmelkamp PMG. Single session debriefing after psychological trauma: a meta-analysis. Lancet. 2002; 360:766-71.

196. Wei Y, Szumilas M, Kutcher S. Effectiveness on mental health of psychological debriefing for crisis intervention in schools. Educ Psychol Rev. 2010;22:339-47.

197. Wessely S, Rose S, Bisson J. A systematic review of brief psychological interventions ("debriefing") for the treatment of immediate trauma-related symptoms and the prevention of posttraumatic stress disorder. In: Cochrane Collaboration, editor. Cochrane library (issue 4). Oxford: Update Software; 1999.

198. Yoman J. A primer on functional analysis. Cogn Behav Pract. 2008;15:325-40.

199. Page AC, Stritzke WGK, MCLean NJ. Toward science-informed supervision of clinical case formulation: a training model and supervision method. Aust Psychol. 2008:43:88-95.
200. Scott MJ, Sembi S. Cognitive behavior therapy treatment failures in practice: the neglected role of diagnostic inaccuracy. Behav Cogn Psychother. 2006;34:491-5.

201. Persons JB. Cognitive therapy in practice: a case formulation approach. New York: Norton; 1989.

202. Bruch MH. Cognitive-behavioral case formulation. In: Bruch MH, editor. Behavior and cognitive therapy today: essays in honour of Hans J. Eysenck. Oxford: Elsevier Science Ltd; 1998. p. 31-48.

203. Haynes SN, Leisen MB, Blaine DD. Design of individualized behavioral treatment programs using functional analytic clinical case models. Psychol Assess. 1997;9:334-48

204. Clark DM. A cognitive approach to panic. Behav Res Ther. 1986;24:461-70.

205. Ehlers A, Clark DM. A cognitive model of posttraumatic stress disorder. Behav Res Ther. 2000;38:319-45.

206. McKay M, Davis M, Fanning P. Thoughts \& Feelings. 3rd ed. Oakland: New Harbinger; 2007

207. Salkovskis PM. Anxiety, beliefs and safety-seeking behavior. In: Salkovskis PM, editor. Frontiers of cognitive therapy. London: Guilford Press; 1996.

208. Wells A. Cognitive therapy of anxiety disorders: a practical manual and conceptual guide. Chichester: Wiley; 1997.

209. Fairburn CG. Cognitive behavior therapy and eating disorders. New York: Guilford Press; 2008.

210. Clark DM, Wells PA. A cognitive model of social phobia. In: Heimberg RG, Liebowitz MR, Hope DA, Schneier SA, editors. Social phobia: diagnosis, assessment and treatment. New York: Guilford Press; 1995. p. 69-93.

211. Moorey S. The six cycles maintenance model: growing a "vicious flower" for depression. Behav Cogn Psychother. 2010;38:173-84.

212. Persons JB, Davidson J. Cognitive-behavioral case formulation. In: Dobson KS, editor. Handbook of cognitive-behavioral therapies. 2nd ed. New York: The Guilford Press; 2001. p. 86-110.

213. Hyman BM, Pedrick C. The OCD Workbook: Your guide to breaking free from obsessive-compulsive disorder. 2nd ed. Oakland: New Harbinger; 2005.

214. Rees CS. Obsessive-compulsive disorder: a practical guide to treatment. Melbourne: IP Communications; 2009

215. Salkovskis PM. Obsessive-compulsive problems: a cognitive-behavioral analysis. Behav Res Ther. 1985;23:571-83.

216. Treatment Protocol Project. World Health Organization collaborating Centre management of mental disorders, vol. 1. 4th ed. Sydney: WHO; 2004.

217. Warwick HMC, Salkovskis PM. Hypochondriasis. In: Scott J, Williams JMG, Beck AT, editors. Cognitive therapy in clinical practice. London: Croom Helm; 1989. p. 45-58.

218. Walker JR, Furer P. Interoceptive exposure in the treatment of health anxiety and hypochondriasis. J Cogn Ther. 2008;22:366-78.

219. Bakker GM, Practical CBT. Using functional analysis, problem-maintaining circles, and standardised homework in everyday therapy. Bowen Hills: Australian Academic Press; 2008.

220. Bakker GM. Problem-maintaining circles: case illustrations of formulations that truly guide therapy. Clin Psychol. 2008;12:30-9.

221. Bakker GM, Practical CBT. Using transdiagnostic case formulations and therapies based on problem-maintaining circles. Bowen Hills: Australian Academic Press. In press.

222. Hofmann SG. Bridging the theory-practice gap by getting even bolder with the Boulder model. Behav Ther. 2013;44:603-8.

223. McGrath RE. Conceptual complexity and construct validity. J Pers Assess. 2005:85:112-24.

224. Borsboom D, Cramer AOJ. Network analysis: an integrative approach to the structure of psychopathology. Annu Rev Clin Psychol. 2013;9:91-121.

225. Borsboom D, Cramer AOJ, Schmittmann VD, Epskamp S, Waldorp LJ. The small world of psychopathology. PLoS One. 2011;6:1-11.

226. Fleeson W, Furr RM, Arnold EM. An agenda for symptom-based research. Behav Brain Sci. 2010;33:157.

227. Boschloo L, van Borkulo CD, Rhemtulla M, Keyes KM, Borsboom D, Schoevers RA. The network structure of symptoms of the diagnostic and statistical manual of mental disorders. PLoS One. 2015;10:e0137621.

228. Fried El, van Borkulo CD, Cramer AOJ, Boschloo L, Schoevers RA, Borsboom D. Mental disorders as networks of problems: a review of recent insights. Soc Psychiatry Psychiatr Epidemiol. 2017:52:1-10.

229. Borsboom D. A network theory of mental disorders. World Psychiatry. 2017; 16:5-13.

230. Borsboom D, Cramer A, Kalis A. Brain disorders? Not really... why network structures block reductionism in psychopathology research. Behav Brain Sci. 2018;24:1-54. 
231. Borsboom D, Fried El, Epskamp S, et al. False alarm? A comprehensive reanalysis of "evidence that psychopathology system networks have limited replicability" by Forbes, Wright, Markon, and Krueger (2017). J Abnorm Psychol. 2017;126:989-99.

232. Forbes M, Wright A, Markon K, Krueger R. Evidence that psychopathology symptom networks have limited replicability. J Abnorm Psychol. 2017;126:1011-6.

233. Belzung C, de Villemeur E, Lemoine M, Camus V. Latent variables and the network perspective. Behav Brain Sci. 2010;33:150-1.

234. Persons JB, Mooney KA, Padesky CA. Inter-rater reliability of cognitivebehavioral case formulations. Cogn Ther Res. 1995;19:21-34.

235. Mumma GH, Smith JL. Cognitive-behavioral-interpersonal scenarios: Interformulator reliability and convergent validity. J Psychopathol Behav Assess. 2001;23:203-21.

236. Eells TD, Kendjelic EM, Lucas CP. What's in a case formulation? Development and use of a content coding manual. J Psychother Pract Res. 1998;7:144-53.

237. Scotti JR, Morris TL, MCNeil CB, Hawkins RP. DSM-IV and disorders of childhood and adolescence: can structural criteria be functional? J Consult Clin Psychol. 1996;64:1177-91.

238. Bergner RM. Characteristics of optimal clinical case formulations. Am J Psychother. 1998;52:287-300.

239. Mathew AR, Pettit JW, Lewinsohn PM, Seeley JR, Roberts RE. Co-morbidity between major depressive disorder and anxiety disorders: shared etiology or direct causation? Psychol Med. 2011;41:2023-34.

240. Atlantis E, Sullivan T. Bidirectional association between depression and sexual dysfunction: a systematic review and meta-analysis. J Sex Med. 2012;9:1497-507.

241. Cosci F, Knuts IJE, Abrams K, Griez EJL, Schruers KR. Cigarette smoking and panic: a critical review of the literature. J Clin Psychiatry. 2010;71:606-15.

242. Liedl A, O'Donnell M, Creamer M, Silove D, et al. Support for the mutual maintenance of pain and post-traumatic stress disorder symptoms. Psychol Med. 2010;40:1215-23.

243. Farmer RF, Nelson-Gray RO. Functional analysis and response covariation in the assessment of personality disorders: a reply to Staats and to Bissett and Hayes. Behav Res Ther. 1999;37:385-94.

244. Popper KR. The logic of scientific discovery. London: Hutchinson; 1980.

245. Waterman GS. Clinicians' "folk" taxonomies and the DSM: pick your poison. Philos Psychiatry Psychol. 2007;14:271-5.

246. Anand S, Malhi GS. From manual to bible: the questionable hegemony of DSM IV. Aust N Z J Psychiatry. 2011:45:348-50.

247. Vanheule S. Psychiatric diagnosis revisited: From DSM to clinical case formulation. Cham, Switzerland: Palgrave Macmillan; 2017.

248. Andreasen NC. DSM and the death of phenomenology in America: an example of unintended consequences. Schizophr Bull. 2007;33:108-12.

249. Staats AW. Unifying psychology requires new infrastructure, theory, method, and a research agenda. Rev Gen Psychol. 1999;3:3-13.

250. Apostolova I, Block S, Buchert R, et al. Effects of behavioral therapy or pharmacotherapy on brain glucose metabolism in subjects with obsessivecompulsive disorder as assessed by brain FDG PET. Psychiatry Res Neuroimaging. 2010;184:105-16.

251. O'Neill J, Gorbis E, Feusner JD, et al. Effects of intensive cognitive-behavioral therapy on cingulate neurochemistry in obsessive-compulsive disorder. J Psychiatr Res. 2013;47:494-504.

252. Mazur A, Booth A. Testosterone and dominance in men. Behav Brain Sci. 1998;21:353-63.

253. van Harmelen AL, van Tol MJ, van der Wee NJA, et al. Reduced medial prefrontal cortex volume in adults reporting childhood emotional maltreatment. Biol Psychiatry. 2010;68:832-8.

254. Neurologisms IJ. Am J Bioeth. 2009;9:1.

255. Hood SB, Lovett BJ. Network models of psychopathology and comorbidity: philosophical and pragmatic considerations. Behav Brain Sci. 2010;33:159-60

256. Rubinsten O, Henik A. Comorbidity: cognition and biology count! Behav Brain Sci. 2010;33:168-70.

257. American Psychiatric Association. Practice guidelines for the treatment of patients with schizophrenia. Am J Psychiatr. 1997;154(Suppl):1-63.

258. Bradford D, Stroup S, Lieberman J. Pharmacological treatments for schizophrenia. In: Nathan PE, Gorman JM, editors. A guide to treatments that work. 2nd ed. New York: Oxford University Press; 2002. p. 169-200.

259. Carr A. The effectiveness of family therapy and systemic interventions for adult-focused problems. J Fam Ther. 2009;31:46-74.

260. Kopelowicz A, Liberman RP, Zarate R. Psychosocial treatments for schizophrenia. In: Nathan PE, Gorman JM, editors. A guide to treatments that work. 2nd ed. New York: Oxford University Press; 2002. p. 201-28.
261. Lee $H$, Schepp $K$. The relationship between symptoms and stress in adolescents with schizophrenia. Issues Ment Health Nurs. 2009;30:736-44.

262. Phillips $\sqcup$, Edwards J, McMurray N, Francey S. Comparison of experiences of stress and coping between young people at risk of psychosis and a nonclinical cohort. Behav Cogn Psychother. 2012;40:69-88.

263. Blake F, Salkovskis P, Gath D, Day A, Garrod A. Cognitive therapy for premenstrual syndrome: a controlled trial. J Psychosom Res. 1998;45:307-14.

264. Christensen AP, Oei TPS. The efficacy of cognitive behavior therapy in treating premenstrual dysphoric changes. J Affect Disord. 1995;33:57-63.

265. Lustyk MKB, Gerrish WG, Shaver S, Keys SL. Cognitive-behavioral therapy for premenstrual syndrome and premenstrual dysphoric disorder: a systematic review. Arch Womens Ment Health. 2009;12:85-96.

266. Hunter MS, Ussher JM, Cariss M, Brown S, et al. Medical (fluoxetine) and psychological (cognitive-behavioral therapy) treatment for premenstrual dysphoric disorder: a study of treatment processes. J Psychosom Res. 2002; 53:811-7.

267. Morse JK, Dennerstein L, Farrell E, Varnavides K. A comparison of hormone therapy, coping skills training, and relaxation for the relief of premenstrual syndromes. J Behav Med. 1991;14:469-89.

268. Hunter M. Cognitive behavioral interventions for premenstrual and menopausal symptoms. J Reprod Infant Psychol. 2003;21:183-93.

269. Hunter MS, Grunfeld EA, Mittal S, Sikka P, et al. Menopausal symptoms in women with breast cancer: prevalence and treatment preferences. PsychoOncology. 2004;13:769-78.

270. Burgess M, Andiappan M, Chalder T. Cognitive behavior therapy for chronic fatigue syndrome in adults. Behav Cogn Psychother. 2012;40:175-91.

271. Vercoulen JHMM, Swanink CMA, Galama JMD, et al. The persistence of fatigue in chronic fatigue syndrome and multiple sclerosis: development of a model. J Psychosom Res. 1998;45:507-17.

272. Wiborg JF, Knoop H, Frank LE, Bleijenberg G. Towards an evidence-based treatment model for cognitive behavioral interventions focusing on chronic fatigue syndrome. J Psychosom Res. 2012;72:399-404.

273. Greenhill LL, Ford RE. Childhood attention-deficit hyperactivity disorder: pharmacological treatments. In: Nathan PE, Gorman JM, editors. A guide to treatments that work. New York: Oxford University Press; 2002. p. 25-55.

274. Hinshaw SP, Klein RG, Abikoff HB. Childhood attention-deficit hyperactivity disorder: nonpharmacological treatments and their combination with medication. In: Nathan PE, Gorman JM, editors. A guide to treatments that work. New York: Oxford University Press; 2002. p. 3-23.

275. Target M, Fonagy P. The psychological treatment of child and adolescent psychiatric disorders. In: Roth A, Fonagy P, editors. What works for whom? 2nd ed. New York: Guilford Press; 2005. p. 385-424.

276. Albelda N, Joel D. Animal models of obsessive-compulsive disorder: exploring pharmacology and neural substrates. Neurosci Biobehav Rev. 2012;36:47-63.

277. Britton JC, Rauch SL. Neuroanatomy and neuroimaging of anxiety disorders. In: Britton JC, Rauch SL, editors. Oxford handbook of anxiety and related disorders. New York: Oxford University Press; 2009. p. 97-110.

278. Holmes A, Singewald N. Individual differences in recovery from traumatic fear. Trends Neurosci. 2013;36:23-31.

279. Adams HE, Cassidy JF. The classification of abnormal behavior. In: Sutker PB, Adams HE, editors. Comprehensive handbook of psychopathology. New York: Plenum Press; 1993. p. 3-26.

280. First MB, Pincus HA, Levine JB, Williams JBW, Ustun B, Peele R. Clinical utility as a criterion for revising psychiatric diagnoses. Am J Psychiatr. 2004;161:946-54.

281. Taylor CT, Amir N. Attention and emotion regulation. In: Kring AM, Sloan DM, editors. Emotion regulation and psychopathology: a transdiagnostic approach to etiology and treatment. New York: Guilford Press; 2010. p. 380-404.

282. Flanagan EH, Blashfield RK. Clinicians' folk taxonomies of mental disorders. Philos Psychiatry Psychol. 2007;14:249-69.

283. Flanagan EH, Blashfield RK. Increasing clinical utility by aligning the DSM and ICD with clinicians' conceptualizations. Prof Psychol Res Pract. 2010;41:474-81.

284. Flanagan E, Blashfield RK. Should clinicians' views of mental illness influence the DSM? Philos Psychiatry Psychol. 2007;14:285-7.

285. Flanagan EH, Blashfield RK. Do clinicians see Axis I and Axis II as different kinds of disorders? Compr Psychiatry. 2006;47:496-502.

286. Flanagan EH, Keeley J, Blashfield RK. An alternative hierarchical organization of the mental disorders of the DSM-IV. J Abnorm Psychol. 2008;117:693-8.

287. Reed GM, Mendonca CJ, Esparza P, Saxena S, Maj M. The WPA-WHO global survey of psychiatrists' attitudes towards mental disorders classification. World Psychiatry. 2011;10:118-31. 
288. Reed GM, Roberts MC, Keeley J, et al. Mental health professionals' natural taxonomies of mental disorders: implications for the clinical utility of the ICD-11 and the DSM-5. J Clin Psychol. 2013;69:1191-212.

289. Roberts MC, Reed GM, Medina-Mora ME, et al. A global clinicians' map of mental disordrs to improve ICD-11: Analysing meta-structure to enhance clinical utility. Int Rev Psychiatry. 2012;24:578-90.

290. Evans SC, Reed GM, Roberts MC, et al. Psychologists' perspectives on the diagnostic classification of mental disorders: results from the WHO-IUPsyS global survey. Int J Psychol. 2013;48:177-93.

291. Denman F. What is the point of formulation. In: Mace C, editor. The art and science of assessment in psychotherapy. New York: Routledge; 1995. p. 167-81

292. Miller GA. Mistreating psychology in the decade of the brain. Perspect Psychol Sci. 2010;5:716-43.

293. Gold J, Stricker G, editors. Comprehensive handbook of psychotherapy integration. New York: Praeger; 1993.

294. Norcross JC, Goldfried MR, editors. Handbook of psychotherapy integration. New York: Basic Books; 1992.

295. Wachtel PL. Cyclic processes in personality and psychopathology. J Abnorm Psychol. 1994;103:51-4.

296. Wachtel PL. Cyclical psychodynamics and the contextual self: the inner world, the intimate world, and the world of culture and society. New York: Routledge/Taylor \& Francis Group; 2014.

297. Machtiger HG. Vicious circles: the centrality of the self in metapsychological rhetoric and clinical practice. Quadrant. 1985;18:57-63.

298. Smith HF. Vicious circles of punishment: a reading of Melanie Klein's envy and gratitude. Psychoanal Q. 2008;77:199-218.

299. Wachtel PL. Therapeutic communication: principles and effective practice. New York, US: Guilford Press; 1993.

300. Lantz J, Walsh J. Short-term existential intervention in clinical practice. Chicago: Lyceum Books; 2007.

301. Watzlawick P, Weakland JH, Fisch R. Change: Principles of problem formation and problem resolution. Oxford: WW Norton; 1974.

302. Hoffman L. Foundations of family therapy. New York: Basic Books; 1981.

303. Alison LJ, Stein KL. Vicious circles: accounts of stranger sexual assault reflect abusive variants of conventional interactions. J Forensic Psychiatry. 2001;12: 515-38.

304. Weston A. Vicious circles of care. Ment Health. 1967;26:3-5.

305. Masuch M. Vicious circle in organizations. Adm Sci Q. 1985;30:14-33.

306. Kirmayer LJ, Sartorius N. Cultural models and somatic syndromes. Psychosom Med. 2007;69:832-40.

307. Jellinger KA. Recent advances in our understanding of neurodegeneration. J Neural Transm. 2009;116:1111-62.

308. Carr EG, Durand VM. Reducing problem behaviors through functional communication training. J Appl Behav Anal. 1985;18:111-26.

309. Durand VM, Crimmins DB. Identifying the variables maintaining self-injurious behavior. J Autism Dev Disord. 1988;18:99-117.

310. Schneider BH, Byrne BM. Individualizing social skills training for behaviordisordered children. J Consult Clin Psychol. 1987;55:444-5.

311. Iwata BA, Dorsey MF, Slifer KJ, et al. Toward a functional analysis of selfinjury. J Appl Behav Anal. 1994;27:197-209.

312. Meyer V, Turkat ID. Behavioral analysis of clinical cases. J Behav Assess. 1979; 1:259-70.

313. Persons JB. Science in practice in cognitive behavior therapy. Cogn Behav Pract. 2016;23:454-8

314. Jacobson NS, Schmaling KB, Holtzworth-Munroe A, et al. Researchstructured versus clinically flexible versions of social learning-based marital therapy. Behav Res Ther. 1989;27:173-80.

315. Litt MD, Kadden RM, Kabela-Cormier E. Individualized assessment and treatment program for alcohol dependence: results of an initial study to train coping skills. Addiction. 2009;104:1837-8.

316. Conrod PJ, Stewart SH, Pihl RO, et al. Efficacy of brief coping skills interventions that match different personality profiles of female substance abusers. Psychol Addict Behav. 2000;14:231-42.

317. Persons JB, Roberts NA, Zalecki CA, Brechwald WAG. Naturalistic outcome of case formulation-driven cognitive-behavior therapy for anxious depressed outpatients. Behav Res Ther. 2006;44:1041-51.

318. Weisz JR, Chorpita BF, Palinkas LA, et al. Testing standard and modular designs for psychotherapy treating depression, anxiety, and conduct problems in youth: a randomized effectiveness trial. Arch Gen Psychiatry. 2012;69:274-82.
319. Chorpita BF, Weisz JR, Daleiden EL, et al. Long-term outcomes for the child STEPS randomized effectiveness trial: a comparison of modular and standard treatment designs with usual care. J Consult Clin Psychol. 2013;81: 999-1009.

320. Johansson R, Sjoberg E, Sjogren M, et al. Tailored vs. standardized internetbased cognitive behavior therapy for depression and comorbid symptoms: a randomized controlled trial. PLoS One. 2012;7:e36905.

321. Fairburn CG, Cooper Z, Shafran R. Cognitive behaviour therapy for eating disorders: a "transdiagnostic" theory and treatment. Behav Res Ther. 2003;41: 509-28.

322. Ghaderi A. Does individualization matter? A randomized trial of standardized (focused) versus individualized (broad) cognitive behavior therapy for bulimia nervosa. Behav Res Ther. 2006:44:273-88.

323. Widiger TA, Frances AJ, Pincus $H$, First M, Ross R, editors. DSM-IV sourcebook, volumes 1-3. Washington DC: American Psychiatric Press; 1994

324. Kemp JJ, Lickel JJ, Deacon BJ. Effects of a chemical imbalance causal explanation on individuals' perceptions of their depressive symptoms. Behav Res Ther. 2014;56:47-52.

325. Phillips J. Idiographic formulations, symbols, narratives, context and meaning. Psychopathology. 2005;38:180-4.

326. Devilly GJ. Power therapies and possible threats to the science of psychology and psychiatry. Aust N Z J Psychiatry. 2005;39:437-45.

327. Glancy G, Saini MA. An evidence-based review of psychological treatments of anger and aggression. Brief Treat Crisis Interv. 2005;5:229-48.

328. Nathan PE, Gorman JM. A guide to treatments that work. 3rd ed. New York: Oxford University Press; 2007.

329. Kazdin AE. Symptom substitution, generalization, and response covariance: implications for psychotherapy outcome. Psychol Bull. 1982;91:349-65.

330. Montgomery GT, Crowder JE. The symptom substitution hypothesis and the evidence. Psychother Theory Res Pract. 1972;9:98-102.

331. Wolpe J. Individualization: the categorical imperative of behavior therapy practice. J Behav Ther Exp Psychiatry. 1986;17:145-53.

332. King NJ, Gullone E, Ollendick TH. Etiology of childhood phobias. Behav Res Ther. 1998;36:297-309.

333. Menzies RG, Clarke JC. The etiology of fear of heights and its relationship to severity and individual response patterns. Behav Res Ther. 1993;31:355-65.

334. Menzies RG, Clarke JC. Retrospective studies of the origins of phobias: a review. Anxiety Stress Coping. 1994;7:305-18.

335. Menzies RG, Clarke JC. The etiology of phobias: a nonassociative account. Clin Psychol Rev. 1995;15:23-48.

336. Carr JE, Le Blanc LA, Love JR. Experimental functional analysis of problem behavior. In: Carr JE, Le Blanc LA, Love JR, editors. Cognitive behavior therapy: Applying empirically supported techniques in your practice. 2nd ed. Hoboken: Wiley; 2008. p. 211-21.

337. Frank E. Interpersonal and social rhythm therapy: a means of improving depression and preventing relapse in bipolar disorder. J Clin Psychol. 2007; 63:463-73.

338. Robinson J, Sareen J, Cox BJ, Bolton JM. Role of self-medication in the development of comorbid anxiety and substance use disorders: a longitudinal investigation. Arch Gen Psychiatry. 2011;68:800-7.

339. Schindel-Allon I, Aderka IM, Shahar G, Stein M, Gilboa-Schechtman E. Longitudinal associations between post-traumatic distress and depressive symptoms following a traumatic event: a test of three models. Psychol Med. 2010;40:1669-78.

340. Wheatley D. Stress, anxiety and depression. Stress Med. 1997;13:173-7.

341. Lepine JP, Pelissolo A. Social phobia and alcoholism: a complex relationship. J Affect Disord. 1998;50:23-8.

342. Hilderink PH, Burger H, Deeg DJ, Beekman AT, Voshaar RCO. The temporal relation between pain and depression: results from the longitudinal aging study Amsterdam. Psychosom Med. 2012;74:945-51.

343. Linton SJ, Nicholas MK, MacDonald S, Boersma K, et al. The role of depression and catastrophizing in musculoskeletal pain. Eur J Pain. 2011;15:416-22.

\section{Publisher's Note}

Springer Nature remains neutral with regard to jurisdictional claims in published maps and institutional affiliations. 